\title{
Opioid Activation of Toll-Like Receptor 4 Contributes to Drug Reinforcement
}

\author{
M. R. Hutchinson, ${ }^{1,4 \star}$ A. L. Northcutt, ${ }^{1 \star}$ T. Hiranita, ${ }^{7}$ X. Wang, ${ }^{1,3}$ S. S. Lewis, ${ }^{1}$ J. Thomas, ${ }^{5}$ K. van Steeg ${ }^{4,6}$ T. A. Kopajtic, \\ L. C. Loram, ${ }^{1}$ C. Sfregola, ${ }^{1}$ E. Galer, ${ }^{1}$ N. E. Miles, ${ }^{1}$ S. T. Bland, ${ }^{8}$ J. Amat, ${ }^{1}$ R. R. Rozeske, ${ }^{1}$ T. Maslanik, ${ }^{2}$ T. R. Chapman, ${ }^{1}$ \\ K. A. Strand, ${ }^{1}$ M. Fleshner, ${ }^{2}$ R. K. Bachtell, ${ }^{1}$ A. A. Somogyi, ${ }^{5}$ H. Yin, ${ }^{3}$ J. L. Katz, ${ }^{7}$ K. C. Rice, ${ }^{9}$ S. F. Maier, ${ }^{1}$ \\ and L. R. Watkins ${ }^{1}$ \\ Departments of ${ }^{1}$ Psychology and Neuroscience, ${ }^{2}$ Integrative Physiology, Center for Neuroscience, and ${ }^{3}$ Chemistry and Biochemistry, Center for Neuroscience and \\ the Biofrontiers Institute, University of Colorado-Boulder, Boulder, Colorado 80309, Disciplines of ${ }^{4}$ Physiology and ${ }^{5}$ Pharmacology, School of Medical Sciences, \\ University of Adelaide, Adelaide, South Australia 5005, Australia, ${ }^{6}$ Division of Pharmacology, Faculty of Science, Utrecht University, 3805 TD Utrecht, the Netherlands, \\ ${ }^{7}$ Department of Health and Human Services, National Institute on Drug Abuse, National Institutes of Health, Intramural Research Program, Biomedical Research Center \\ MDRB, Baltimore, Maryland 21224, ${ }^{8}$ Department of Psychology, University of Colorado-Denver, Denver, Colorado 80217, and ${ }^{9}$ Chemical Biology Research Branch, National \\ Institute on Drug Abuse and National Institute on Alcohol Abuse and Alcoholism, National Institutes of Health, Rockville, Maryland 20892
}

Opioid action was thought to exert reinforcing effects solely via the initial agonism of opioid receptors. Here, we present evidence for an additional novel contributor to opioid reward: the innate immune pattern-recognition receptor, toll-like receptor 4 (TLR4), and its MyD88-dependent signaling. Blockade of TLR4/MD2 by administration of the nonopioid, unnatural isomer of naloxone, $(+)$-naloxone (rats), or two independent genetic knock-outs of MyD88-TLR4-dependent signaling (mice), suppressed opioid-induced conditioned place preference. $(+)$-Naloxone also reduced opioid (remifentanil) self-administration (rats), another commonly used behavioral measure of drug reward. Moreover, pharmacological blockade of morphine-TLR4/MD2 activity potently reduced morphine-induced elevations of extracellular dopamine in rat nucleus accumbens, a region critical for opioid reinforcement. Importantly, opioid-TLR4 actions are not a unidirectional influence on opioid pharmacodynamics, since $T L R 4^{-1-}$ mice had reduced oxycodone-induced p38 and JNK phosphorylation, while displaying potentiated analgesia. Similar to our recent reports of morphine-TLR4/MD2 binding, here we provide a combination of in silico and biophysical data to support (+)-naloxone and remifentanil binding to TLR4/MD2. Collectively, these data indicate that the actions of opioids at classical opioid receptors, together with their newly identified TLR4/MD2 actions, affect the mesolimbic dopamine system that amplifies opioid-induced elevations in extracellular dopamine levels, therefore possibly explaining altered opioid reward behaviors. Thus, the discovery of TLR4/MD2 recognition of opioids as foreign xenobiotic substances adds to the existing hypothesized neuronal reinforcement mechanisms, identifies a new drug target in TLR4/MD2 for the treatment of addictions, and provides further evidence supporting a role for central proinflammatory immune signaling in drug reward.

Received Feb. 11, 2012; revised June 14, 2012; accepted June 25, 2012.

Author contributions: M.R.H., A.L.N., T.H., X.W., S.S.L., J.T., K.v.S., T.A.K., L.C.L., S.T.B., J.A., R.R.R., A.A.S., H.Y., J.L.K., K.C.R., S.F.M., and L.R.W. designed research; M.R.H., A.L.N., T.H., X.W., S.S.L., J.T., K.v.S., T.A.K., L.C.L., C.S., E.G., N.E.M., S.T.B., J.A., R.R.R., T.M., T.R.C., K.A.S., M.F., K.C.R., and L.R.W. performed research; M.R.H., A.L.N., T.H., X.W., S.S.L., J.T., K.v.S., T.A.K., L.C.L., C.S., E.G., N.E.M., S.T.B., J.A., R.R.R., K.A.S., A.A.S., H.Y., J.L.K., K.C.R., S.F.M., and L.R.W. analyzed data; M.R.H., A.L.N., T.H., X.W., S.S.L., J.T., K.v.S., T.A.K., R.K.B., A.A.S., H.Y., J.L.K., K.C.R., S.F.M., and L.R.W. wrote the paper.

This research was supported by NIH Grants DA024044, DE017782, DA023132, DA025740, NS067425, DA027977, and DA026950 and by the NIH Intramural Research Programs of the National Institute on Drug Abuse and the National Institute on Alcohol Abuse and Alcoholism. Support was also provided by an International Association for the Study of Pain international collaborative research grant, an American Australian Association Merck Company Foundation Fellowship, a National Health and Medical Research Council CJ Martin Fellowship (ID 465423; M.R.H. 2007-2010), Australian Research Council Research Fellowship (DP110100297; M.R.H. 2011), and Australian Postgraduate Award (J.T.) and Danone Research for Specialised Nutrition (The Netherlands) (K.vS). We thank Dr. David White and the NIDA Addiction Treatment Discovery Program (NIDA ATDP) for the NovaScreen data generated through a contract with Caliper Life Sciences as well as for the biogenic amine transporter data generated through a contract with Research Service (R\&D-22), Department of Veterans Affairs Medical Center, Portland, OR.

${ }^{*}$ M.R.H. and A.L.N. contributed equally to this work.

The authors declare no competing financial interests.

Correspondence should be addressed to Linda R. Watkins, Department of Psychology and Neuroscience, Campus Box 345, University of Colorado at Boulder, Boulder, C0 80309-0345. E-mail: linda.watkins@colorado.edu.

DOI:10.1523/JNEUROSCI.0684-12.2012

Copyright $\odot 2012$ the authors $\quad 0270-6474 / 12 / 3211187-14 \$ 15.00 / 0$

\section{Introduction}

The reinforcing/rewarding effects of opioids contribute to their widespread abuse (Compton and Volkow, 2006; Manchikanti, 2006). Acute opioid reinforcement is traditionally thought to be mediated through the activation of mesolimbic dopamine neurons projecting from the ventral tegmental area to the nucleus accumbens (NAc) shell (Ikemoto, 2007). However, additional complexities to this system have also been postulated (Laviolette et al., 2002; Vargas-Perez et al., 2009).

While there has long been a focus on classical opioid receptors in exploring opioid actions, reconsideration is necessary. The seminal research of Takagi et al. (1960) demonstrated the pharmacodynamic relevance of nonclassical nonstereoselective opioid actions, and Goldstein et al. (1971) found a 30-fold greater abundance of nonstereoselective but saturable opioid binding sites compared with saturable stereoselective opioid binding. However, until recently there has been little research on these aspects of opioid pharmacology (Hutchinson et al., 2011). Reevaluation of these data implies additional sites of opioid action, which are capable of recognizing structurally 
diverse ligands beyond the more well studied opioid active (-)-isomers.

Structurally diverse opioids (including stereochemistries) could also be viewed as xenobiotics, akin to detection of chemicals by the liver's pregnane X receptor (Matic et al., 2007), thus recognized as substances "foreign" to the CNS. Within the CNS, pattern recognition receptors, such as toll-like receptors (TLRs), can serve this sentinel role identifying "molecular patterns" as "nonself" or "danger" signals (Buchanan et al., 2010). TLR4 has recently received increasing attention as it responds to highly diverse molecular patterns associated with Gram-negative bacteria and endogenous substances released from stressed/damaged host cells. Such ligands activate the TLR4 complex, inducing the production and release of proinflammatory, neuroexcitatory mediators via MyD88-dependent intracellular pathways (Yirmiya and Goshen, 2011).

We have previously examined the xenobiotic-mediated TLR4 actions of opioids using a collection of in vivo, in vitro, molecular, and in silico strategies, demonstrating that various opioids, including morphine, activate TLR4 signaling (Hutchinson et al., 2010a; Wang et al., 2012b) through binding to an accessory protein of TLR4, myeloid differentiation protein 2 (MD2), thereby inducing TLR4 oligomerization and triggering proinflammation (Wang et al., 2012b). The potential importance of activation of TLR4 signaling by opioids, in addition to opioid activation of classical neuronal opioid receptors, for opioid reinforcement is unknown, and is explored here for the first time.

The present studies aimed to define whether opioid-induced TLR4 activation contributes to opioid reinforcement and its associated elevations of NAc dopamine (Ikemoto, 2007). This was conducted using mice deficient in TLR4 and MyD88 signaling and by pharmacological blockade of TLR4 by $(+)$-naloxone. Importantly, in each condition the analgesic properties of the opioid agonist were assessed to determine whether the TLR4-directed intervention had simply reduced all the pharmacodynamic actions of the opioid agonist, rather than selectively the rewarding properties. It is apparent that an understanding of opioid-TLR4 actions within the mesolimbic dopamine reward system, in addition to the established opioid receptor-dependent response, will have implications for how opioid reinforcement is viewed, and the opportunities that await the use of pharmacological TLR4 blockade in drug reward.

\section{Materials and Methods \\ Subjects}

For studies at the University of Colorado, viral-free adult, male Sprague Dawley rats (250-325 g; Harlan) were pair-housed in standard Plexiglas cages with ad libitum choice food and water. The colony room was maintained at $21^{\circ} \mathrm{C}$ on a $12 / 12 \mathrm{~h} \mathrm{light/dark} \mathrm{cycle.} \mathrm{All} \mathrm{experiments} \mathrm{were} \mathrm{con-}$ ducted during the light phase. Upon arrival, rats were allowed 1 week of acclimation before any procedures. All procedures were approved by the University of Colorado Institutional Animal Care and Use Committee.

For the drug self-administration procedure, performed at the National Institute on Drug Abuse, viral-free adult male Sprague Dawley rats (weighing $\sim 300 \mathrm{~g}$ at the start of the study), obtained from Taconic Farms, served as subjects after acclimation to the laboratory for at least 1 week. Food (Scored Bacon Lover Treats, BIOSERV) and tap water were available in their home cages. After acclimation, weights of rats were maintained at $\sim 320 \mathrm{~g}$ by adjusting their daily food ration. The animal housing room was temperature and humidity controlled and maintained on a 12/12 h light/dark cycle with lights on at 07:00 A.M. All procedures were approved by the National Institute on Drug Abuse Intramural Research Program Institutional Animal Care and Use Committee. All studies were performed during the light phase.
For mouse studies, conducted at the University of Adelaide, pathogenfree adult male wild-type BALB/c mice were obtained from The University of Adelaide Laboratory Animal Services (Adelaide, SA, Australia), and two null mutant mouse strains, TLR4 ${ }^{-l_{-}^{-}}$and $M y D 88^{-1-}$, were originally sourced from Professor Akira (Osaka University, Osaka, Japan) via Dr. Paul Foster from University of Newcastle (Newcastle, NSW, Australia). Mice were housed in a 12/12 h light/dark cycle (light on at 7:00 A.M.) in temperature-controlled rooms $\left(23 \pm 3^{\circ} \mathrm{C}\right)$. Food and water was available ad libitum. After arrival, the mice were allowed to acclimate for at least $5 \mathrm{~d}$ and were handled at least $3 \mathrm{~d}$ before testing commenced. The mice were always tested during the light phase of the light/dark cycle. All procedures were approved by the Animal Ethics Committee of the University of Adelaide. All studies were performed during the light phase.

\section{Drugs}

(-)-Morphine sulfate was gifted by Mallinckrodt. $(+)$-Naloxone was synthesized by Dr. Kenner Rice (Chemical Biology Research Branch, National Institute on Drug Abuse and National Institute on Alcohol Abuse and Alcoholism, National Institutes of Health, Bethesda, MD). Oxycodone and ( - )-naloxone was purchased from Sigma. Remifentanil (brand name Ultiva) was purchased from Mylan Institutional. Glycine vehicle was purchased from Sigma. Drugs were confirmed to be endotoxin-free by the limulus amebocyte lysate assay (Lonza) conducted per the manufacturer's instructions. Drugs doses are reported as free base.

\section{Experiment 1: Rat conditioned place preference Apparatus}

The Plexiglas place preference apparatus measured 72 [length $(\mathrm{L})] \times 30$ [width $(\mathrm{W})] \times 30$ [height $(\mathrm{H})] \mathrm{cm}$ and comprised two distinct conditioning environments with a neutral space in-between. Each conditioning environment measured $30(\mathrm{~L}) \times 30(\mathrm{~W}) \times 30(\mathrm{H}) \mathrm{cm}$. One environment had a floor consisting of $5 \mathrm{~mm}$ metal bars spaced $1.5 \mathrm{~cm}$ apart (edge-to-edge) and walls with alternating $2 \mathrm{~cm}$ wide black and white stripes. The floor of the second environment was a black anodized aluminum plate, perforated across the surface with evenly spaced $5 \mathrm{~mm}$ holes, and the walls were black with evenly spaced $50 \mathrm{~mm}$ white polka dots. The neutral area measured $12 \times 30 \times 30 \mathrm{~cm}$, with sanded, black Plexiglas flooring. During the conditioning phase, Plexiglas partitions matching their respective environments were inserted to restrict the rats to their specific, designated environment.

The activity of each rat was recorded using Logitech Quickcam Pro 5000 webcams mounted $1.0 \mathrm{~m}$ above the center of the conditioned place preference apparatus. The cameras were connected to a computer running AnyMaze (Stoelting), to track and record the time a rat spent in each of the three compartments.

\section{Procedure to assess the effect of $(+)$-naloxone on morphine} conditioned place preference

An unbiased conditioned place preference protocol was used. Rats were handled and weighed the day before the start of an experiment. On day 1 , all rats were placed individually in the conditioned place preference apparatus and allowed to freely explore the entire apparatus for $20 \mathrm{~min}$, to assess baseline preferences or biases to either environment. Any rat that spent $<20 \%$ or $>80 \%$ of the entire time in either environment was removed from the study. Each rat was then randomly assigned to treatment group and conditioning environment in a counterbalanced fashion, so that half the rats in each treatment group were assigned to the environment they preferred, and half were assigned to the environment they less preferred. Rats received either (1) saline subcutaneously injected immediately with (-)-morphine $(5 \mathrm{mg} / \mathrm{kg}$, s.c.) or saline subcutaneously on alternating days; (2) saline subcutaneously injected immediately with saline subcutaneously every day; (3) (+)-naloxone $(1 \mathrm{mg} / \mathrm{kg}$, s.c. $)$ injected immediately with $(-)$-morphine $(5 \mathrm{mg} / \mathrm{kg}$, s.c.) or with saline subcutaneously on alternating days; or (4) (+)-naloxone ( $1 \mathrm{mg} / \mathrm{kg}$, s.c.) injected immediately with saline subcutaneously every day. Upon completion of injections, subjects were placed into the designated conditioning environment for $45 \mathrm{~min}$. Place preference testing occurred on day 10 
(preexposure day 1, days 2-9 conditioning, day 10 preference test) and was run identically to baseline testing on day 1 . That is, rats were placed in the place preference apparatus, in a drug-free state, and allowed to explore the entire apparatus for $20 \mathrm{~min}$. The time spent in each environment was recorded and conditioning was calculated as a difference between the time spent in the drug-paired environment before and after conditioning. All testing was performed using blinded procedures with respect to group assignments.

Procedure to assess the possible aversive effect of $(+)$-naloxone The same paradigm was used as above, except that rats received either (1) (+)-naloxone ( $1 \mathrm{mg} / \mathrm{kg}$, s.c.) versus saline subcutaneously on alternating days, or (2) saline subcutaneously every day. Place preference was then assessed as above.

\section{Experiment 2: Rat self-administration \\ Apparatus}

Experimental sessions were conducted with subjects placed in operantconditioning chambers (modified ENV-008CT, Med Associates) that measured $25.5 \times 32.0 \times 25.0 \mathrm{~cm}$, and were enclosed within soundattenuating cubicles equipped with a fan for ventilation and white noise to mask extraneous sounds. On the front wall of each chamber were two response levers, $5.0 \mathrm{~cm}$ from the midline and $4.0 \mathrm{~cm}$ above the grid floor. A downward displacement of a lever with a force approximating $20 \mathrm{~g}$ defined a response, which always activated a relay mounted behind the front wall of the chamber producing an audible "feedback" click. Three light-emitting diodes (LEDs) were located in a row above each lever. A receptacle for the delivery of food pellets was mounted behind a $5.0 \times 5.0$ $\mathrm{cm}$ opening in the front wall midline between the two levers and $2.0 \mathrm{~cm}$ above the floor. A pellet dispenser (ENV-203, Med Associates) could deliver $45 \mathrm{mg}$ food pellets to the receptacle. A syringe driver (Model 22, Harvard Apparatus) placed above each chamber delivered injections of specified volumes and durations from a $10 \mathrm{ml}$ syringe. The syringe was connected by Tygon tubing to a single-channel fluid swivel (375 Series Single Channel Swivels), which was mounted on a balance arm above the chamber. Tygon tubing from the swivel to the subject's catheter was protected by a surrounding metal spring and completed the connection to the subject.

\section{Procedures}

Subjects were placed in chambers during experimental sessions that were conducted daily, $7 \mathrm{~d}$ per week. During sessions, subjects were trained with food reinforcement (45 $\mathrm{mg}$ of food pellets, BIOSERV) to press the right lever, and were subsequently trained under a fixed-ratio (FR) 5-response schedule of reinforcement (each fifth response produced a food pellet). Food deliveries were followed by a $20 \mathrm{~s}$ timeout (TO) period during which all lights were off and responses had no scheduled consequences other than the feedback click. During this training, sessions lasted for $20 \mathrm{~min}$ or until 30 food pellets were delivered.

After subjects were responding at a rate sufficiently high that they obtained 30 food pellets within each of three consecutive sessions, they were surgically implanted in the right or left external jugular vein with a chronic indwelling catheter that exited at the mid-scapular region of the animal's back. Catheter implantation was performed under anesthesia (ketamine $60 \mathrm{mg} / \mathrm{kg}$, i.p. and xylazine $12 \mathrm{mg} / \mathrm{kg}$, i.p.). Catheters were infused daily with $0.1 \mathrm{ml}$ of a sterile saline solution containing heparin $(30 \mathrm{IU} / \mathrm{ml})$ and penicillin $\mathrm{G}$ potassium $(250,000 \mathrm{IU} / \mathrm{ml})$ to minimize the likelihood of infection and the formation of clots or fibroids. All animals were allowed to recover from surgery for $\sim 7 \mathrm{~d}$ before cocaine selfadministration studies were initiated.

Rats were trained to self-administer cocaine first, a standard training paradigm as previously described (Hiranita et al., 2011). Cocaine selfadministration sessions were conducted in $2 \mathrm{~h}$ daily sessions until the response rates and patterns of responding showed no substantial sessionto-session trends. During these sessions, the LEDs above the right lever were illuminated when cocaine injections were available. Completion of five responses turned off the LEDs and activated the infusion pump, delivering a dose of $0.89 \mathrm{mg} / \mathrm{kg}$. A $20 \mathrm{~s} \mathrm{TO}$, during which LEDs were off and responses produced no consequences, started with the injection.
After the time out, the LEDs were illuminated and responding again had scheduled consequences. Once rates of responding maintained by cocaine were stable across sessions, the session was divided into five $20 \mathrm{~min}$ components, each preceded by a 2 min TO. This arrangement allowed the assessment of a different cocaine dose within each component. By adjusting infusion volumes and durations, the cocaine dose per injection was incremented in the five sequential components in an ascending order as follows: no injection (also referred to as extinction, or EXT, because responses had no scheduled consequences other than turning off the LEDs for $20 \mathrm{~s}$ ), 0.026, 0.089, 0.29, and $0.89 \mathrm{mg} / \mathrm{kg} / \mathrm{inj}$. Infusion volumes and durations were respectively $0,5.6,18,56,180 \mu \mathrm{l}$ and $0,0.32,1,3.2$ $10 \mathrm{~s}$, based on a body weight of $0.32 \mathrm{~kg}$. A response-independent "sample" injection of cocaine at the corresponding dose was administered immediately before each component.

Training continued until: (1) at least $4.5 \mathrm{mg} / \mathrm{kg}$ of cocaine was selfadministered within a session with $<20 \%$ variation in the total number of cocaine injections compared with the previous session; (2) the dose of cocaine that maintained maximal response rates varied by no more than one-half log unit over two consecutive test sessions; and (3) maximum response rates were at least five-fold higher than response rates maintained during EXT.

Once performances were stable across successive sessions, the effect of substitutions for cocaine of remifentanil (dose range 0.09-2.9 micro$\mathrm{gram} / \mathrm{kg} / \mathrm{inj}$, i.v.) was assessed, with a minimum of $72 \mathrm{~h}$ between treatments. Subsequently, the effects of presession intraperitoneal injections of $(+)$-naloxone on the response rates maintained by remifentanil injection were assessed. The opioid remifentanil was chosen because its ultra-short half-life increases rapidity and stability of bar-pressing for drug (Panlilio et al., 2003). Due to high rates of remifentanil self-administration, infusion durations were reduced to $0,0.24,0.75$, $2.4,7.5 \mathrm{~s}$ to avoid excessive fluid intake and emptying of the syringe.

\section{Experiment 3: Rat in vivo microdialysis}

Surgery

A single microdialysis guide cannula was stereotaxically implanted per rat under isoflurane anesthesia (MWI Veterinary Supply). Each sterile CMA 12 gauge guide cannula (CMA Microdialysis) was aseptically implanted and aimed at the right or left NAc shell (stereotaxic coordinates relative to bregma: anterior/posterior $=+1.7 \mathrm{~mm}$; medial $/$ lateral $=$ $\pm 0.8 \mathrm{~mm}$; relative to dura: dorsal/ventral $=-5.6 \mathrm{~mm}$, bite bar $=0$; (Paxinos and Watson, 1998) in a counterbalanced fashion. The guide cannula and a tether screw (CMA microdialysis) were attached to the skull using three jeweler's screws and dental cement. After surgery (isoflurane anesthesia), rats were individually housed and allowed to recover for at least 1 week.

\section{In vivo microdialysis procedures}

The microdialysis study was undertaken with a minimum of 1 week recovery from anesthesia and guide cannula insertion. The afternoon before the microdialysis experiment, the rats were transferred to the dialysis room that was on the same light/dark cycle as the colony room. The rats were placed in separate Plexiglas bowls with ad libitum food and water. Microdialysis probes (CMA 12, MW cutoff 20,000 Da, $2 \mathrm{~mm}$ active membrane) were inserted through each guide cannula and artificial CSF (145 mm NaCl, $2.7 \mathrm{~mm} \mathrm{KCl,} 1.2 \mathrm{~mm} \mathrm{CaCl}, 1.0 \mathrm{~mm} \mathrm{KCl}$ ) was perfused through the probes using a CMA infusion pump at a rate of 0.2 $\mu \mathrm{l} / \mathrm{min}$ overnight. The next morning, the flow rate was increased to 1.5 $\mu \mathrm{l} / \mathrm{min}$ where it remained for the rest of the experiment. The rats were given $2 \mathrm{~h}$ to acclimatize to the experimental flow rate before any samples were taken. All dialysates were collected in tubes prefilled with $3 \mu \mathrm{l}$ of $0.02 \%$ EDTA (antioxidant) in 1\% ethanol. The sample tubes were manually changed every $20 \mathrm{~min}$ for a total of $3 \mathrm{~h}$ (9 samples total). Three baseline samples were collected for the first hour of the experiment. After the fourth sample tube was inserted, rats began receiving injections. Each rat received two subcutaneous injections, one immediately following the other. The first injection was either $(+)$-naloxone $(1 \mathrm{mg} / \mathrm{kg})$ or saline and the second injection was either morphine $(6 \mathrm{mg} / \mathrm{kg})$ or saline. The morphine and $(+)$-naloxone doses were based on pilot studies. Then the $(+)$-naloxone dose was similarly based on pilot studies. Following drug 
administration, samples were taken every 20 min across a $100 \mathrm{~min}$ time course.

\section{Microdialysis probe placement verification}

After completion of the microdialysis study, rats were killed with intraperitoneal $65 \mathrm{mg} / \mathrm{kg}$ sodium pentobarbital (Abbott Laboratories) before brain extraction. The brains were frozen in chilled isopentane and cryostat sectioned $(30 \mu \mathrm{m})$ at $-20^{\circ} \mathrm{C}$. Brain sections containing each rat's cannula track were mounted on gelatin-treated slides and stained with cresyl violet, coverslipped, and viewed under a light microscope to define the site of microdialysis sampling. To be included in data analysis, at least $75 \%$ of the probe had to be within the NAc shell. Dialysate samples from rats fulfilling this requirement for dopamine were analyzed using high performance liquid chromatography (HPLC) along with electrochemical detection using a method previously described (Bland et al., 2009).

\section{Experiment 4: Mouse conditioned place preference \\ Apparatus}

The Plexiglas place preference apparatus measured $50(\mathrm{~L}) \times 25(\mathrm{~W}) \times 35$ $(\mathrm{H}) \mathrm{cm}$ and comprised two distinct conditioning environments $(22 \times$ $19 \times 35 \mathrm{~cm}$ divided into 4) with a neutral passage way in-between $(16.6 \times 4.8 \times 35 \mathrm{~cm})$. Each conditioning environment measured 10.9 $(\mathrm{L}) \times 9.3(\mathrm{~W}) \times 35(\mathrm{H}) \mathrm{cm}$. One environment had a floor consisting of $5 \mathrm{~mm}$ plastic black bars spaced $5 \mathrm{~mm}$ apart (edge-to-edge). The floor of the second environment was black plastic perforated across the surface with evenly spaced $5 \mathrm{~mm}$ holes. The walls of each environment were black or white (balanced randomized assignment). The neutral passage way measured $16.6 \times 4.8 \times 35 \mathrm{~cm}$, with sanded, black Plexiglas flooring. During the conditioning phase, Plexiglas partitions matching their respective environments were inserted to restrict the mice to their specific, designated environment.

The activity of each mouse was recorded using Logitech Quickcam Pro 5000 webcams mounted $1.0 \mathrm{~m}$ above the center of the conditioned place preference apparatus. The cameras were connected to a computer running AnyMaze (Stoelting), to track and record the time a mouse spent in each of the three compartments.

\section{Procedure}

An unbiased conditioned place preference protocol was used. On day 1, all mice were placed individually in the conditioned place preference apparatus and allowed to freely explore the entire apparatus for $20 \mathrm{~min}$, to assess baseline preferences or biases to either environment. Each mouse was then randomly assigned to treatments group and conditioning environment in a counterbalanced fashion, so that half the mice in each treatment group was assigned to the environment they preferred, and half was assigned to the environment they did not prefer. Mice received either (1) oxycodone ( $20 \mathrm{mg} / \mathrm{kg}$ i.p.) versus saline on alternating days, or (2) saline (vehicle of oxycodone) every day. Oxycodone was used here as it produced robust, consistent, and reliable conditioned place preference in wild-type BALB/c mice, while morphine did not. Upon completion of injections, mice were placed into the designated conditioning environment for $30 \mathrm{~min}$ (total of four conditioning sessions, conditioning sessions 1 and 2 separated from conditioning sessions 3 and 4 by a $2 \mathrm{~d}$ weekend). Place preference testing occurred on day 8 and was run identically to baseline testing on day 1 . That is, mice were placed in the place preference apparatus, in a drug-free state, and allowed to explore the entire apparatus for $20 \mathrm{~min}$. The time spent in each environment was recorded and conditioning was calculated as a difference of the time spent in the drug-paired environment before and after conditioning. All testing was performed using blinded procedures with respect to group assignments.

\section{Phase 1 control experiments to assess the selectivity of the observed opioid drug response following pharmacological and genetic modification to TLR4}

1A: Rat Hargreaves test for thermal sensitivity

Acute indwelling lumbosacral catheters. Catheter implantations via the L5/L6 intervertebral approach and drug microinjections were performed based on Milligan et al. (1999). Rats were briefly anesthetized under isoflurane anesthesia and an 18-gauge needle was placed between L5 and L6 into the intrathecal space to serve as a guide. Polyethylene-10 tubing was threaded rostrally through the guide and terminated over the lumbosacral enlargement. The 18-gauge needle was removed after catheter placement and the tubing secured to the superficial musculature of the lower back with 3-0 silk suture. The tubing was then threaded subcutaneously to exit the nape of the neck and the skin incision closed. Catheters were $75 \mathrm{~cm}$ in length, preloaded with drugs at the intrathecal end and the remainder filled with sterile saline, as used previously (Hutchinson et al., 2008b). This allowed remote injection of drug during behavioral testing without disturbing the animal, and the injection of a small void volume that ensured delivery of drugs. Behavioral testing began $2 \mathrm{~h}$ after intrathecal catheter placement.

Procedure. Thermal testing measured withdrawal latency to radiant heat applied separately to the tail and the plantar surface of each hindpaw in a modified Hargreaves test (Hargreaves et al., 1988). Baseline latencies before drug administration were calculated as the average of three latencies, measured 5 min apart. Following first drug administration, latencies to withdrawal from each paw and the tail were measured at 3 min intervals for $45 \mathrm{~min}$. The intensity of the heat source was adjusted such that predrug latencies to withdrawal were 3-4 s, with a $10 \mathrm{~s}$ cutoff to avoid tissue damage. This allowed both analgesia and hyperalgesia to be measured. All testing was blind with respect to group assignment.

\section{B: Mouse hotplate test for thermal sensitivity}

Mice received at least three $5 \mathrm{~min}$ habituations to the test environment before behavioral testing. Latencies for behavioral responses to the $50^{\circ} \mathrm{C}$ hotplate were assessed. All testing was conducted blind to group assignment. A cutoff time of $60 \mathrm{~s}$ was imposed to avoid tissue damage. Baseline latencies for the hotplate response ranged from 24 to $32 \mathrm{~s}$. Baseline response latencies were recorded before drug administration. Data are expressed as percentage maximum potential effect (\% MPE). For the construction of the dose-responses to oxycodone, mice (wild-type and $T L R 4^{-I^{-}}$) hotplate latencies were assessed before and $20 \mathrm{~min}$ after challenge doses of oxycodone $(0.01,0.1,1,2$, and $5 \mathrm{mg} / \mathrm{kg})$. Each oxycodone challenge dose involved 8 mice. Mice, which displayed freezing symptoms or urinated during hotplate latency testing, were excluded from datasets because of inherent errors in data collection under these conditions. Mouse behavioral responses that were two SDs or greater than the mean were also excluded ( $\max n=2$ per group, and replaced).

\section{C: Morphine tissue concentration quantification}

Experimental procedure. $(+)$-Naloxone $(5 \mathrm{mg} / \mathrm{kg})$ or equivolume vehicle $(1 \mathrm{ml} / \mathrm{kg}$ saline) was administered subcutaneously $10 \mathrm{~min}$ before morphine $(10 \mathrm{mg} / \mathrm{kg}$, s.c.). The $(+)$-naloxone and morphine doses and timings were chosen to match those used in studies of reinforcement, below. A series of blood samples $(\sim 0.5 \mathrm{ml} / \mathrm{sample})$ were collected via lateral tail vein nick into heparinized tubes. Sampling occurred just before morphine (time 0 ) and 5, 15, and $30 \mathrm{~min}$ after morphine. Heparinized blood samples were kept on ice until centrifugation, collection of plasma, and storage of plasma at $-80^{\circ} \mathrm{C}$ before extraction for analysis of morphine content. Half the rats of each group were killed immediately after the 5 min sample collection. The rest were killed immediately after the $30 \mathrm{~min}$ sample collection. Upon death by unanesthetized decapitation, brain samples (hippocampus, cerebellum) were rapidly isolated, flash frozen in liquid nitrogen, and stored at $-80^{\circ} \mathrm{C}$ before extraction for analysis of morphine content.

Morphine extractions and analyses. Tissue morphine concentrations were quantified by a modification of a HPLC electrochemical detection method previously described (Van Crugten et al., 1997; Doverty et al., 2001). The system consists of an ESA 5600A Coularray detector with an ESA 5014B analytical cell and an ESA 5020 guard cell. The column was an ESA MD-150 (C-18, $3 \mu \mathrm{m}, 150 \times 3.2 \mathrm{~mm})$, and the mobile phase was ESA buffer MD-TM. The analytical cell potentials are kept at $-100 \mathrm{mV}$ and $+250 \mathrm{mV}$ and the guard cell at $+300 \mathrm{mV}$. Tissue was weighed and then sonicated in $1 \mathrm{ml}$ of deionized water, while plasma samples were diluted in water for a total volume of $1 \mathrm{ml}$. Samples were then alkalinized with $500 \mu$ l of sodium bicarbonate buffer (500 mm; pH 9.6) and extracted with chloroform $(6 \mathrm{ml})$ by vortexing for $120 \mathrm{~s}$ followed by centrifugation 
$(1700 \times g ; 10 \mathrm{~min})$. The upper aqueous layer is aspirated to waste followed by a further addition of the sodium bicarbonate buffer. Samples were then vortexed $(10 \mathrm{~s})$ and centrifuged $(1700 \times g ; 10 \mathrm{~min})$. After aspirating the aqueous layer to waste, morphine was back extracted from $5 \mathrm{ml}$ of chloroform into $300 \mu \mathrm{l}$ of $\mathrm{NaH}_{2} \mathrm{PO}_{4}(50 \mathrm{~mm}$; $\mathrm{pH}$ 2) by vortexing for $120 \mathrm{~s}$. After centrifugation, an aliquot $(100 \mu \mathrm{l})$ of the aqueous phase was injected onto the system. Calibration standards ranged from 0.25 $\mathrm{ng} / \mathrm{ml}$ to $400 \mathrm{ng} / \mathrm{ml}$, and samples above this were diluted with water. High $(300 \mathrm{ng} / \mathrm{ml})$ and low $(1 \mathrm{ng} / \mathrm{ml})$ quality control samples were assayed with each assay and were expected to be within $10 \%$ of the nominal concentrations. The lower limit of quantification was $0.25 \mathrm{ng} / \mathrm{ml}$.

\section{Phase 2 control experiment to define speed of $(+)$-naloxone effects on mitogen-activated protein kinase phosphorylation in mice following oxycodone}

Immediately following hotplate behavioral testing, mice were overdosed with sodium pentobarbital $(400 \mathrm{mg} / \mathrm{kg})$, perfused with $0.9 \%$ isotonic saline, and then dissected to obtain spinal cord. The spinal cord tissue was homogenized in $1 \mathrm{ml}$ of $1 \times$ denaturing buffer and then heated to $100^{\circ} \mathrm{C}$ in a heating block for $6 \mathrm{~min}$ to prevent protein aggregation and degradation. Spinal tissue was stored at $-80^{\circ} \mathrm{C}$ until use. Spinal lysates from wild-type and TLR $4^{-1-}$ mice receiving $0.01,1$, and $5 \mathrm{mg} / \mathrm{kg}$ oxycodone were tested for levels of p38, JNK, and ERK phosphorylation. Total p38 was not measured because of time limitations for transcription/translation. Before analysis, spinal cord samples were diluted 1:4 using assay diluent and protein concentrations determined using BCA analysis kit (BD Bioscience). Cell lysates were prepared as per BD Cytometric Bead Array kit to label phosphorylated proteins. Following washing, the samples were analyzed using a BD fluorescence-activated cell-sorting machine and analyzed in a blinded fashion.

\section{Phase 3 control experiments to define biophysical and in silico interactions of opioids and (+)-naloxone at TLR4/MD2 TLR4/MD2 in silico docking}

To prioritize the docking calculations and to provide a possible mechanistic framework for the in silico docking simulations, it was a priori hypothesized that the TLR4 and MD2 could exist in a range of possible conformational states ranging from a preactivation state of individual membrane bound TLR4 and soluble extracellular MD2 through to a complete signaling heterodimer of TLR4 and MD2.

To examine the in silico docking of ligands to the TLR4/MD2 complex, the crystal structure of the human TLR4-human MD2-E.coli LPS Ra complex program database (pdb) file was obtained from RCSB Protein Data Bank (PDBID: 3FXI) as published by Park et al. (2009). All ligands, water, and cofactors were removed from the file via Molegro Molecular Viewer, thus eliminating exogenous water molecules and artifacts from crystallization from future docking simulations. The modified pdb files werefurtherpreparedusingMGLTools 1.5.6.RC2(http://mgltools.scripps. $\mathrm{edu} /$ ) with polar hydrogen atoms added. Ligands for docking were gathered using PubChem isomeric SMILES, then converted to .pdb using a structure file generator (http://cactus.nci.nih.gov/services/translate/), and validated by visual inspection.

The four macromolecules in the MD2-TLR4 heterodimer pdb file were separated into four separate pdb files, resulting in TLR4-A, TLR4-B, MD2-C, and MD2-D facilitating the creation of the range of possible conformational states using Molegro Molecular Viewer. Docking simulations were conducted for all ligands (agonists and antagonists) to each of these conformational states. Docking was conducted using Vina [version 1.1.2 (Trott and Olson, 2010)] within PyRx [version 0.8 (Wolf, 2009)]. An exhaustiveness factor of 8 was used for all simulations, with the Vina search space dimensions and center defined for each macromolecule using the auto-maximize function.

\section{Fluorescence titrations}

An insect expression human MD2-pAcGP67A vector was provided by Dr. Jie-Oh Lee (Korea Advanced Institute of Science and Technology, Daejeon, Republic of Korea). MD2 baculovirus was prepared by cotransfection of SF-9 insect cells with MD2-pAcGP67A vector and bright lin- earized baculovirus DNA as described by the manufacturer's protocol (BD Bioscience). After 2-3 rounds of amplification, the MD2 baculovirus suspension reached a titer of $\sim 10^{8} / \mathrm{ml}$ virus particles and was used to transfect high 5 insect cells to express MD2. MD2 was secreted into the medium. After 3-4 d transfection, the medium was harvested and MD2 protein was purified by IgG Sepharose affinity purification.

Fluorescence measurements were performed on a Fluorolog-3 spectrofluorimeter (Horiba Jobin Yvon). All measurements were performed under room temperature using a $2^{\circ}-10 \mathrm{~mm}$ quartz cell (Starna Cells). The wavelength of $280 \mathrm{~nm}$ was chosen to excite the Tyr and Trp residues in MD2 fluorescence and measurement at emission of 300-450 nm was conducted. For the fluorescent probe Bis-ANS26, $385 \mathrm{~nm}$ was chosen as the excitation wavelength and emission at $420-550 \mathrm{~nm}$ was recorded. Appropriate baseline signals were subtracted from spectra obtained. Fluorescence was also corrected by the relation, $F_{\text {corr }}=F_{\text {obs }}$ anti-log $\left(\mathrm{OD}_{\mathrm{ex}}+\right.$ $\left.\mathrm{OD}_{\mathrm{em}} / 2\right)$ for the inner filter effect when necessary, where $\mathrm{OD}_{\mathrm{ex}}$ and $\mathrm{OD}_{\mathrm{em}}$ are the optical densities at excitation and emission wavelengths, respectively (Lakowicz, 2006).

For naloxone and remifentanil fluorescence quenching assays, $0.5 \mu \mathrm{M}$ $\mathrm{MD} 2$ was titrated with different concentrations of naloxone or remifentanil, and the fluorescence emission at $337 \mathrm{~nm}$ was plotted against naloxone or remifentanil concentration. The raw data were fitted by nonlinear least square method using the equation: $F=0.5 \times\left(2 \times F_{0}-F_{\mathrm{PL}} \times\left(K_{\mathrm{D}}+\right.\right.$ $\left.\left.\left[L_{\mathrm{T}}\right]+\left[P_{\mathrm{T}}\right]-\left(\left(K_{\mathrm{D}}+\left[L_{\mathrm{T}}\right]+\left[P_{\mathrm{T}}\right]\right)^{2}-4 \times\left[L_{\mathrm{T}}\right] \times\left[P_{\mathrm{T}}\right]\right)^{0.5}\right)\right)$, where $[F]$, the observed fluorescence; $F_{0}$, initial fluorescence of protein in the absence of ligand; $F_{\mathrm{RL}}$, adjustable parameter for protein-ligand complex molar fluorescence; $K_{\mathrm{D}}$, dissociation constant; $\left[L_{\mathrm{T}}\right]$, total concentration of the ligand; $\left[P_{\mathrm{T}}\right]$, total protein concentration. The data were also plotted according to the equation: $\lg \left(F_{0} / F-1\right)=-\lg K_{\mathrm{D}}+n \times \lg$ ([ligand]) (Lakowicz, 2006), where $K_{\mathrm{D}}$, dissociation constant; $n$, stoichiometry. $(+)$-Naloxone and remifentanil show no fluorescence signal at the tested conditions. Roxithromycin, which has been reported to show no apparent binding to MD2 (Resman et al., 2008), served as a negative control compound. Protein A was used as a negative control protein to eliminate the possibility of binding to Protein A tag.

For the displacement assay, different concentrations of $(+)$ naloxone were titrated into MD2 $(0.5 \mu \mathrm{M})$ and Bis-ANS $(0.5 \mu \mathrm{M})$ mixture. After overnight equilibrium at room temperature, the BisANS fluorescence intensity was measured. The fluorescence emission at $478 \mathrm{~nm}$ was plotted against $(+)$-naloxone concentration. $K_{\mathrm{i}}$ of $(+)$-naloxone was determined using the equation: $K_{\mathrm{i}}=K_{\text {app }} /(1+$ $[$ Bis - ANS $] / K_{\mathrm{D}}($ Bis - ANS - MD2) $)$.

\section{Statistics}

Two-way repeated-measures ANOVAs with Bonferroni post hoc tests when appropriate were used to determine statistical significance between groups for both the $\mathrm{CPP}$ and in vivo microdialysis measures. For the drug self-administration procedure, response rates were determined by dividing responses by elapsed time in each component, excluding the time outs that followed injections. Average values across six subjects (with SEM) are presented below. To determine whether there was a difference in effects of cocaine compared with remifentanil self-administration, a two-way, repeated-measures ANOVA was used (factors were component and substance injected: cocaine or saline). A one-way, repeatedmeasures ANOVA was used to assess the effects of successive components in the substitution for cocaine of remifentanil. A two-way repeated-measures ANOVA was used to assess the effects of presession treatments of $(+)$-naloxone on remifentanil self-administration. For studies of prior drug treatments on self-administration of remifentanil, a post hoc Bonferroni $t$ test was used for pairwise comparisons.

For response thresholds to radiant heat (Hargreaves test) and hotplate tests, one-way ANOVAs with appropriate Bonferroni post hocs were used to confirm that there were no baseline differences on behavioral measures. Two-way repeated-measures ANOVAs with Bonferroni post hoc tests when appropriate were used to determine statistical significance between groups for thermal response threshold measures. $p<0.05$ was considered significant. Hotplate latencies across the oxycodone dose range were analyzed using Prism, GraphPad 5.0 software with a four parameter dose-response model. 


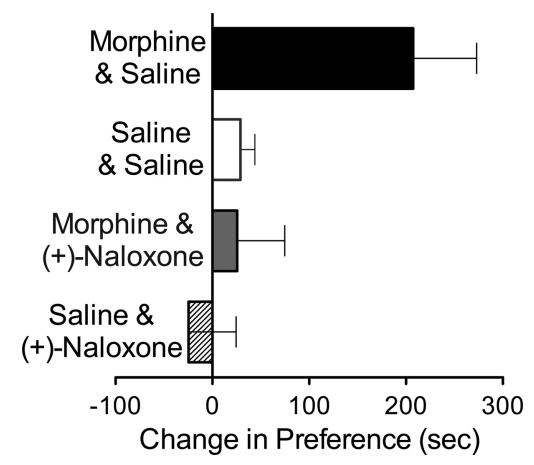

Figure 1. (+)-Naloxone blocks the place conditioning effects of morphine. Morphine (5 $\mathrm{mg} / \mathrm{kg}$, i.p.; 4 pairings) injected with saline (black bar) produced significant place preference (two-way ANOVA with Bonferroni post hoc test, $p<0.01$ ). (+)-Naloxone (1 mg/kg, s.c.) injected just before morphine blocked morphine-induced preferences (gray bar). In the absence of morphine, $(+)$-naloxone and saline were without effect on place conditioning. Data are means per group \pm SEMs, $p=0.01, n=6-11$ group.

For all analyses, $p<0.05$ was considered significant.

\section{Results}

\section{Assessment of the role of TLR4 in opioid reward/reinforcement}

Experiment 1: (+)-Naloxone suppresses morphine conditioned place preference

To assess whether systemic $(+)$-naloxone influences brain mechanisms that underlie opioid reinforcement, the effects of $(+)$ naloxone on morphine conditioned place preference (CPP; $n=$ 6-11/group) were assessed using unbiased procedures previously described (Hutchinson et al., 2008a). In CPP, rats experience morphine in one environment, vehicle in a different environment, and are later tested drug-free to determine which environment they prefer. The difference in time spent in the drug-paired side, compared with predrug baseline, is then calculated. As expected, control rats displayed preference for the side previously paired with morphine ( $5 \mathrm{mg} / \mathrm{kg}$ s.c.; saline/morphine group; Fig. 1). (+)-Naloxone (1 mg/kg, s.c.) administered just before each conditioning trial blocked the development of morphineinduced place preference $[(+)$-naloxone/morphine group]. The saline/saline and $(+)$-naloxone/saline groups were not statistically different from each other, nor were they significantly different from the $(+)$-naloxone/morphine group, supporting the conclusion that $(+)$-naloxone effectively blocked morphine induced CPP. A two-way ANOVA with Bonferroni post hoc tests revealed a significant effect of treatment $\left(F_{(3,30)}=4.89, p=0.01\right)$. Two-way ANOVA revealed no effect of morphine drug conditioning $\left(F_{(1,30)}=0.02, p=0.78\right)$, no interaction $\left(F_{(1,30)}=0.02\right.$, $p=0.89)$ or effect of $(+)$-naloxone treatment $\left(F_{(1,30)}=0.02, p=\right.$ 0.88 ) on the total distance traveled during the place of preference test, as a measure of activity. Thus, morphine-induced TLR4 activation may contribute to morphine reward, as measured by this Pavlovian conditioning paradigm.

Alternatively, (+)-naloxone could be perceived as aversive, rather than suppressing reward per se. To examine this possibility the study was repeated without morphine, with $(+)$-naloxone paired with one context, rather than both contexts as above $(n=$ 5-6/group). (+)-Naloxone failed to condition either aversion or preference (change in preference mean \pm SEM for saline: $15.4 \pm 46.6 \mathrm{~s}$; for $(+)$-naloxone: $1.5 \pm 44.35 \mathrm{~s}$; one-way ANOVA, $p>0.05)$. A two-tailed Student's $t$ test revealed no effect of $(+)$ naloxone treatment $(t=0.15, p=0.88)$ on the total distance traveled during the place of preference test, as a measure of activ-

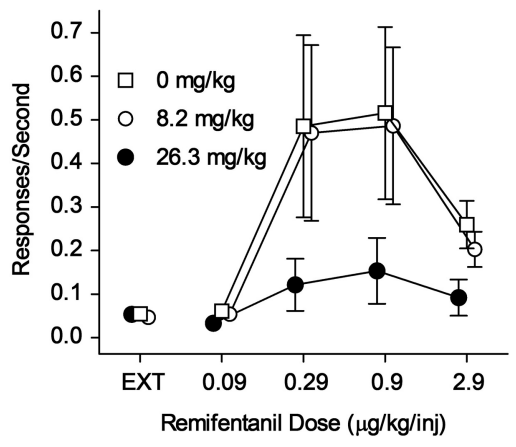

Figure 2. (+)-Naloxone suppresses remifentanil self-administration. Ordinates, responses per second; abscissae, remifentanil injection dose in ug/kg/injection. Ext; extinction. $0 \mathrm{mg} / \mathrm{kg}$ (+)-naloxone (open squares), $8.2 \mathrm{mg} / \mathrm{kg}(+)$-naloxone (open circles), and $26.3 \mathrm{mg} / \mathrm{kg}(+)$ naloxone (filled circles). (+)-Naloxone was administered intraperitoneally at 5 min before sessions. Note that $(+)$-naloxone dose dependently decreased remifentanil selfadministration. Data are means \pm SEMs; $n=6 /$ group.

ity. Together with the study above, these data support the concept that morphine-induced TLR4 signaling contributes to this measure of opioid reinforcement.

Experiment 2: $(+)$-Naloxone suppresses self-administration of the opioid remifentanil

The effect of the TLR4 antagonist (+)-naloxone was tested on remifentanil self-administration. Remifentanil was chosen for test given its very short half-life increases rate and stability of bar pressing. Rats trained on cocaine self-administration, a standard training paradigm as previously described (Hiranita et al., 2011), were tested with remifentanil that reliably maintained selfadministration at high rates. The inverted U-shaped dose-effect curve for remifentanil is characteristic of that for other drugs of abuse (Fig. 2) (Panlilio et al., 2003). The highest rate of responding maintained by cocaine was obtained at a dose of $285.6 \mu \mathrm{g} / \mathrm{kg} /$ inj. Remifentanil maintained responding in a manner similar to that maintained by cocaine and other abused drugs in all important aspects (Fig. 2). The highest rate of responding was maintained at a dose of $0.9 \mu \mathrm{g} / \mathrm{kg} / \mathrm{inj}$, with lower response rates at higher and lower doses (Fig. 2, open circles). The maximal response rates maintained by remifentanil were two-fold higher than those maintained by cocaine $(0.52 \pm 0.20$ vs $0.19 \pm 0.06$, respectively), but the shape of the remifentanil dose-effect curve was similar to that for cocaine. Remifentanil was $\sim 320$-fold more potent than cocaine. Response rates were significantly $\left(F_{(4,20)}=\right.$ $4.20, p=0.013$ ) affected by dose, and post hoc tests indicated that rates maintained by 285.6 and $0.9 \mu \mathrm{g} / \mathrm{kg} / \mathrm{inj}$ of cocaine and remifentanil, respectively, were significantly greater than those when responses did not produce injections $(t \geq 2.81, p \leq 0.043)$. Treatment with $(+)$-naloxone immediately before the selfadministration session, dose-dependently suppressed responding maintained by remifentanil (Fig. 2). A two-way repeatedmeasures ANOVA indicated a significant effect of remifentanil dose $\left(F_{(4,40)}=5.22, p=0.005\right)$ but a nonsignificant effect of presession dose of $(+)$-naloxone $\left(F_{(2,40)}=2.54, p=0.128\right)$. In addition, there was a significant interaction of the two $\left(F_{(8,40)}=\right.$ $2.34, p=0.036)$. Post hoc tests indicated that the effects of 26.2 $\mathrm{mg} / \mathrm{kg}$ of $(+)$-naloxone significantly $(p \leq 0.012)$ decreased response rates maintained by the $0.29(t=2.99)$ and $0.9(t=2.98)$ $\mathrm{ug} / \mathrm{kg} / \mathrm{inj}$ dose of remifentanil.

Experiment 3: $(+)$-Naloxone suppresses morphine-induced elevations of NAc shell dopamine

Given the striking behavioral effects observed with (+)-naloxone in the CPP and self-administration paradigms above, the effect of 


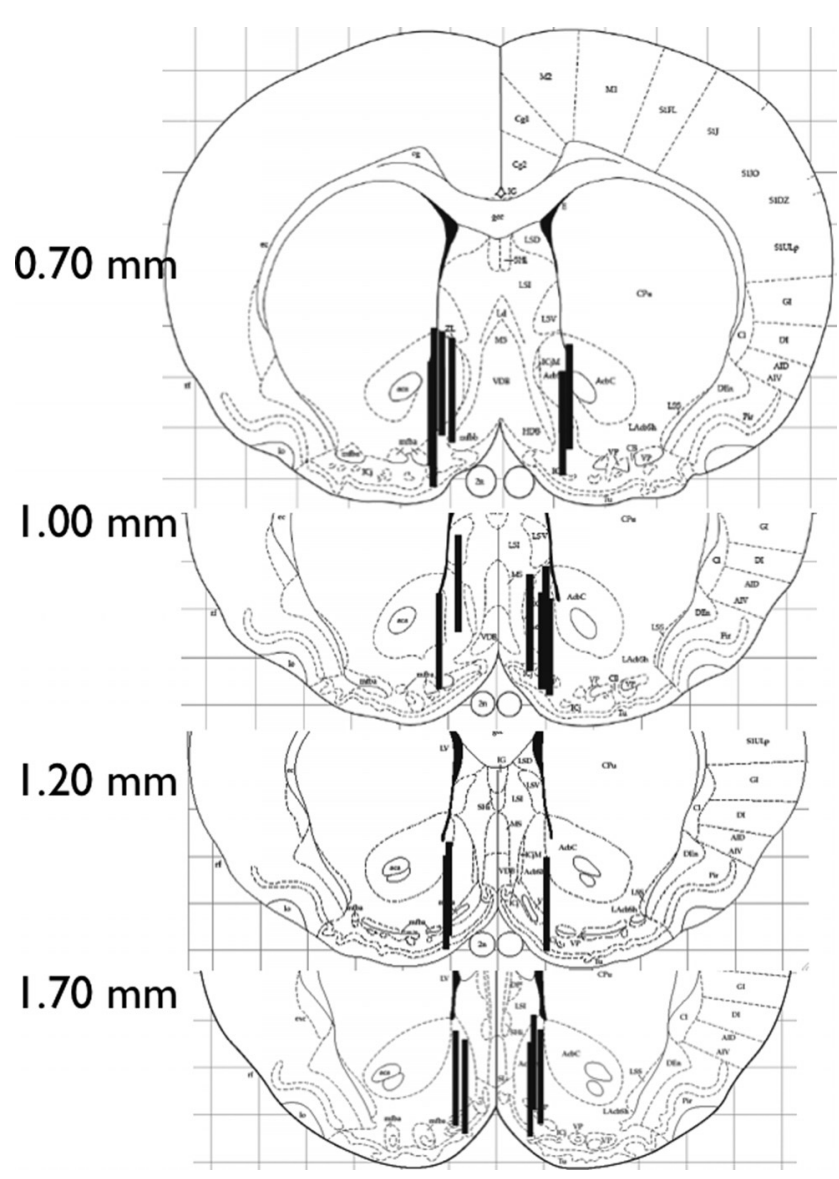

Figure 3. Probe placements in the nucleus accumbens shell in the in vivo microdialysis experiment. Probe placements are depicted using plates adapted from the atlas of Paxinos and Watson (1998). Not all probes can be seen due to overlapping placements.

(+)-naloxone on morphine-induced elevations of NAc shell dopamine, an important neurochemical correlate of opioid reinforcement, was tested to define whether suppression of this measure of reinforcement would also be observed. Dopamine concentrations were assessed by in vivo microdialysis, as previously described (Bland et al., 2009), in rats implanted with cannulae confirmed to terminate within the NAc shell (Fig. 3). Before drug treatment, there were no differences in concentrations of extracellular dopamine in the NAc shell recorded from the three baseline time points sampled $(p>0.05)$. As expected, morphine $(6 \mathrm{mg} / \mathrm{kg}$, s.c.) injected with saline vehicle increased extracellular concentrations of dopamine in the NAc shell (Fig. 4). (+)-Naloxone (1 mg/kg, s.c.) suppressed this effect. A repeated-measures ANOVA revealed a significant difference in percentage increase of dopamine from baseline based on drug treatment, $F_{(2,128)}=6.77, p<0.01$. Bonferroni post hoc tests supported that the saline/morphine treated rats showed an increase in dopamine efflux in the NAc shell, whereas the (+)-naloxone/ morphine treated rats were not different from the saline/saline treatment group.

Experiment 4: Mice deficient in TLR4- or MyD88-dependent signaling display significantly reduced oxycodone conditioned place preference

Given the above converging lines of evidence, all of which support that a (+)-naloxone-sensitive system is involved in opioid reward/ reinforcement, it was pertinent to assess whether this response could be mirrored using an alternative TLR4-targeted approach. There-

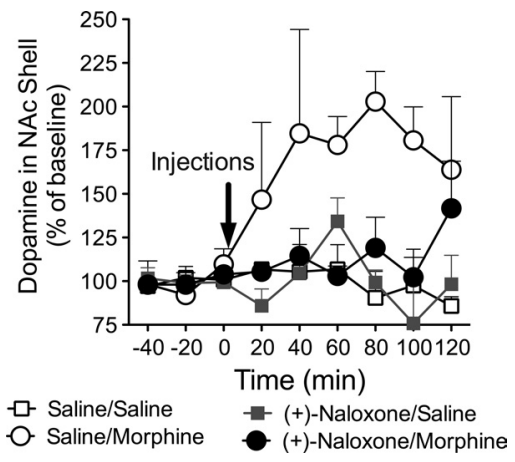

Figure 4. (+)-Naloxone suppresses morphine-induced dopamine release in the nucleus accumbens shell. In vivo microdialysis was used to test the effect of $(+)$-naloxone-(1 $\mathrm{mg} / \mathrm{kg}$, s.c.) on morphine- (6 mg/kg, s.c.) induced increases in extracellular dopamine in the nucleus accumbens shell. After three baseline samples, rats received saline plus saline, saline plus morphine, $(+)$-naloxone plus saline, or $(+)$-naloxone plus morphine. Repeated-measures ANOVA revealed a significant effect of treatment condition ( $p<$ 0.01). Data are means per group \pm SEMs; $n=4$ /group.

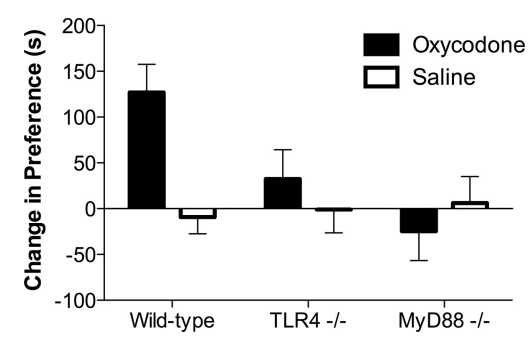

Figure 5. Oxycodone conditioned place preference is significantly reduced in TLR4 or $M_{y D 88^{-1}}$ compared with wild-type mice. Deficiencies in TLR4 or MyD88 render mice with significantly reduced oxycodone conditioned place preference; main strain $\left(F_{(2,72)}=3.21, p<\right.$ $0.046)$ and drug effects $\left(F_{(1,72)}=3.00, p=0.049\right)$ with a significant interaction $\left(F_{(2,72)}=4.76\right.$, $p=0.01)$. Post hoc analysis revealed a significant place preference induced by oxycodone in wild-type mice $(t=3.8, p<0.001)$, but no significant effect of oxycodone in the TLR4 ${ }^{-1}$ - or MyD88 ${ }^{-1-}$ animals $(t<0.79, p>0.05) . n=11-17$ per group. Data are means \pm SEMs.

fore, the role of TLR4 signaling in the behavioral reinforcing actions of oxycodone was examined. Mice deficient in TLR4 or those lacking the TLR4 accessory signaling protein MyD88 were assessed on oxycodone CPP and compared with wild-type control mice. Deficiencies in TLR4 or MyD88 render mice unable to signal via the TLR4MyD88-dependent signaling cascade. Two-way ANOVA revealed main strain $\left(F_{(2,72)}=3.21, p<0.046\right)$ and drug effects $\left(F_{(1,72)}=\right.$ $3.00, p=0.049)$ with a significant interaction $\left(F_{(2,72)}=4.76, p=\right.$ 0.01 ; Fig. 5). Post hoc analyses revealed a significant place preference induced by oxycodone in wild-type mice $(t=3.8, p<$ $0.001)$, but no significant effect of oxycodone in the TLR4 ${ }^{-1-}$ or $M y D 88^{-1-}$ animals $(t<0.79, p>0.05$; Fig. 5). Two-way ANOVA revealed a main effect of drug conditioning $\left(F_{(1,72)}=26.55, p<\right.$ $0.0001)$ on the total distance traveled, as a measure of activity, but no interaction $\left(F_{(2,72)}=0.93, p=0.40\right)$ or effect of $\operatorname{strain}\left(F_{(2,72)}=1.45\right.$, $p=0.25)$ were observed during the place of preference test.

Experimental controls to assess the selectivity of the impact of TLR4 on the pharmacodynamic actions of opioids

The ability to draw meaningful conclusions from the first four experiments would be significantly hampered if no further assessments were made. Therefore, three additional phases of control experiments were conducted to provide additional validation of the four primary experiments. Phase 1 control experiments assessed the selectivity of the observed opioid drug response following pharmacological and genetic modification to TLR4. 
That is, it was first assessed if the previous experiments could simply be explained by a pan-pharmacodynamic opioid attenuation response, as would be expected if an opioid receptor antagonist had been administered. In fact, based on our previous publications, attenuation of the TLR4-dependent central neuroexcitatory immune signaling, which has been demonstrated to oppose opioid analgesia, should lead to an acute potentiation of opioid analgesia (Hutchinson et al., 2010b). Phase 1 control experiments also assessed if the coadministration of $(+)$ naloxone may have altered the access of morphine to the brain, and thus its active sites for producing opioid reward.

Phase 2 control experiments assessed if the opioid-induced TLR4-dependent changes in behavior were temporally associated with established TLR4-dependent downstream signaling activation, thereby providing evidence for the speed of the TLR4 response. Finally, Phase 3 control experiments aimed to determine if these opioid-induced, TLR4-dependent responses were via direct opioid activation of the TLR4 signaling complex or via some other indirect means. Therefore, in silico and in vitro biophysical studies were conducted to address each of these concerns.

Phase 1 control experiments: Does pharmacological or genetic modification of TLR4 decrease opioid analgesia parallel to TLR4 blockade reducing opioid reward?

1A: (+)-Naloxone potentiates acute remifentanil analgesia, in keeping with remifentanil as a TLR4 agonist. If remifentanil acts as a TLR4 agonist, then $(+)$-naloxone should potentiate intrathecal remifentanil analgesia just as $(+)$-naloxone has previously been documented to potentiate morphine analgesia (Hutchinson et al., 2010b). There were no baseline latency differences between groups of animals $(F=1.67, p>0.05)$. Very similar patterns were observed on both the left and the right hindpaw withdrawal latencies, and thus results are presented with the two hindpaws averaged. There were significant differences between the drug treatment groups in the tail $(F=44.8, p<0.05)$ and hindpaw $(F=23.29, p<0.05)$ responses. Bonferroni post hoc tests showed that intrathecal remifentanil alone produced significant and brief analgesia on the tail (at 3, 6, 18, 21, and 33 min following first remifentanil injection) and hindpaws (at 3 and $33 \mathrm{~min}$ following first remifentanil injection), when compared with glycine vehicle alone (Fig. 6). The remifentanil analgesia on both the tail $(3,6,9$, 21 , and 36 min following first remifentanil injection) and hindpaws $(3,6,18,21,33$, and $36 \mathrm{~min}$ following first remifentanil injection) was potentiated by administration of $(+)$-naloxone 10 min before the first remifentanil injection. Thus, as hypothesized, remifentanil acted as a TLR4 agonist causing TLR4-dependent opposition to opioid analgesia, and hence remifentanil analgesia was potentiated by $(+)$-naloxone acting as a TLR4 antagonist. As such, while $(+)$-naloxone reduced remifentanil reward (Experiment 2) it increased analgesia.
TAIL

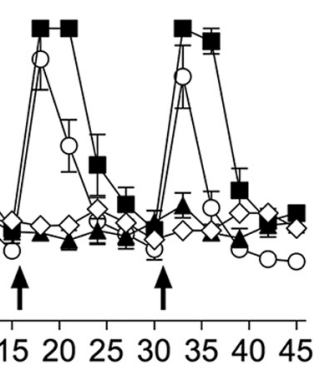

-O- Remifentanil + saline

- Remifentanil + (+)-naloxone

$\diamond$ glycine + saline

- glycine + (+)-naloxone

5 ug remifentanil i.t.

15 ug glycine i.t.

$75 \mathrm{mg} / \mathrm{kg}$ (+)-naloxone s.c.

Figure 6. Remifentanil analgesia is potentiated by coadministration of $(+)$-naloxone, as predicted if remifentanil acts as a ( Following baseline (BL) latency assessments with radiant heat to the tail and hindpaws, (+)-naloxone $(75 \mathrm{mg} / \mathrm{kg})$ produced a significant and brief analgesia in both the tail (top; $F=44.8, p<0.05$ ) and hindpaws (bottom; $F=23.29, p<0.05$ ) when compared with glycine vehicle. Remifentanil analgesia was robustly potentiated by $(+)$-naloxone $(F=44.8 ; p<0.05)$. Arrows indicate timing of the remifentanil or glycine vehicle intrathecal injections. Data are means $\pm \mathrm{SEMs} ; n=6 /$ group.

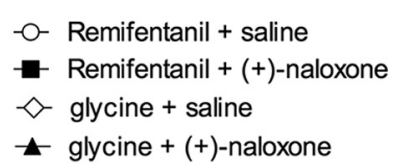

5 ug remifentanil i.t. 15 ug glycine i.t. $75 \mathrm{mg} / \mathrm{kg}(+)$-naloxone s.c.

1B: Oxycodone is a more potent analgesic in TLR4 ${ }^{-1-}$ mice compared with wild-type mice. TLR $4^{-1-}$ mice were used to assess the involvement of TLR4 in acute oxycodone analgesia over a range of doses. Pain responsivity was compared for wild-type versus TLR $4^{-1-}$ mice dosed by intraperitoneal injection of oxycodone ranging from no analgesia to maximal analgesia on the hotplate test. As expected, increasing doses of oxycodone resulted in significant increases in hotplate latencies. Further analysis of the oxycodone dose-response curves revealed a main TLR4 effect where TLR $4^{-1-}$ mice achieved significantly longer hotplate latencies $(p<0.01)$. There was a fivefold leftward shift in the $T L R 4^{-1-}$ oxycodone analgesic dose-response curve $\left(\mathrm{ED}_{50}\right.$ wildtype $1.36 \mathrm{mg} / \mathrm{kg}$ vs TLR4 ${ }^{-1-} 0.26 \mathrm{mg} / \mathrm{kg} ; F_{(2,71)}=24.1 ; p<$ $0.0001)$ compared with wild-type mice (Fig. 7). In addition, $T L R 4^{-1-}$ mice had a significantly altered slope of the dose-response curves (wild-type: 2.89 vs TLR4 ${ }^{-1-}: 0.85 ; F_{(2,71)}=24.1$; $p<0.0001)$. Once again, as hypothesized, oxycodone acted as a TLR4 agonist causing TLR4-dependent opposition of opioid analgesia, and hence oxycodone analgesia was potentiated in the absence of TLR4. As such, while TLR $4^{-1-}$ mice had reduced oxycodone reward (Experiment 4), they had increased analgesia.

1C: (+)-Naloxone does not prevent systemic morphine from reaching the brain. While the $\mathrm{CPP}$, self-administration, and in vivo microdialysis studies above suggest that $(+)$-naloxone inhibits those centrally mediated opioid-induced effects, an alternative explanation is that $(+)$-naloxone prevents morphine from reaching the brain, that it is a pharmacokinetic, and not TLR4based, opioid-reward mechanism. Thus, brain morphine con- 


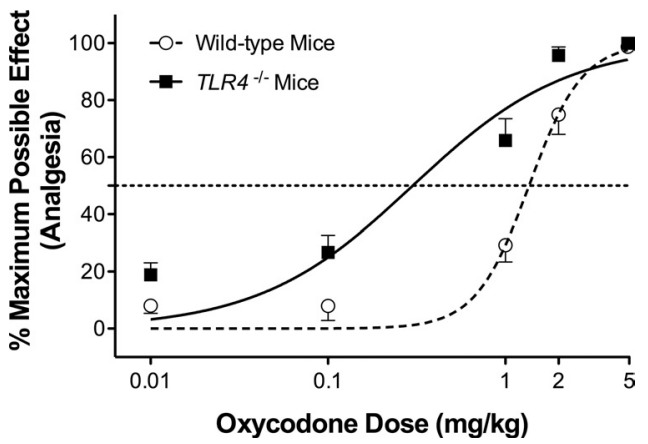

Figure 7. Oxycodone is a more potent analgesic in $T L R 4^{-1-}$ mice compared with wildtype mice. TLR4 ${ }^{-1-}$ mice demonstrate significantly longer hotplate latencies when administered with oxycodone compared with wild-type controls. $\mathrm{ED}_{50}$ wild-type $1.36 \mathrm{mg} / \mathrm{kg}$ versus $T L R 4^{-1-} 0.26 \mathrm{mg} / \mathrm{kg} ; F_{(2,71)}=24.1 ; p<0.0001 . n=7-8$ animals $/$ dose.

centrations were quantified, as previously described (Van Crugten et al., 1997; Doverty et al., 2001), following coadministration with (+)-naloxone. (+)-Naloxone had no effect on morphine concentrations in brain tissue at the time points measured, compared with rats receiving morphine coadministered with vehicle (saline) ( $p>0.05$; Fig. 8). Together with the CPP, selfadministration and the in vivo microdialysis data above, these results support the conclusion that opioid-induced TLR4 signaling substantially contributes to this neurochemical change considered to play a role in opioid reward independent of pan-pharmacodynamic changes or pharmacokinetic alterations.

Phase 2 control experiments: Are the opioid-induced TLR4-dependent changes in behavior temporally associated with TLR4-dependent activation of mitogen-activated protein kinases? It was first necessary to clarify whether opioid-induced TLR4dependent signaling events occurred fast enough to be associated with the altered pharmacodynamic responses. We have previously published that oxycodone is capable of in vitro activation of TLR4-dependent NF- $\kappa \mathrm{B}$ signaling using a stably transfected cell line and $24 \mathrm{~h}$ cell culture (Hutchinson et al., 2010b). However, to date there is no evidence for in vivo TLR4-dependent oxycodone signaling. Thus, using wild-type and TLR $4^{-1-}$ mice, quantification of mitogen-activated protein kinase (MAPK) phosphorylation following in vivo oxycodone administration was evaluated.

Immediately following analgesia testing in Phase 1 control

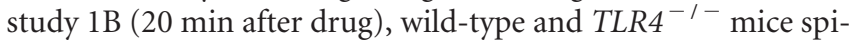
nal cord samples were collected to enable quantification of in vivo signaling via the TLR4 cascade. Samples were analyzed for downstream TLR4 MAPK phosphorylation. Oxycodone administration caused significant dose-dependent elevations in the phosphorylation of p38 (Fig. 9A) and JNK (Fig. $9 B$ ) in wild-type $(t>3.053, p<0.01)$ but not TLR4 $4^{-1-}$ mice $(t<0.98, p>0.05)$. For the phosphorylation of $\mathrm{p} 38$, a two-way ANOVA resulted in a main strain $\left(F_{(3,53)}=11.11, p=0.0016\right)$ and oxycodone dose effect $\left(F_{(1,53)}=6.94, p=0.0005\right)$ with a significant interaction $\left(F_{(3,53)}=3.71, p=0.017\right)$. Post hoc analysis revealed that oxycodone significantly increased p38 phosphorylation in wild-type over TLR4 ${ }^{-1-}$ mice at $5 \mathrm{mg} / \mathrm{kg}(t=3.8, p<0.01$; Fig. 9A). Analysis of JNK phosphorylation revealed a main strain $\left(F_{(3,53)}=9.13, p<\right.$ $0.0001)$ and dose effect $\left(F_{(1,53)}=60.79, p<0.0001\right)$ and significant interaction $\left(F_{(1,53)}=14.73, p<0.001\right.$; Fig. $\left.9 B\right)$. In contrast, there were no dose-dependent elevations in ERK phosphorylation and no TLR4-dependent differences in the response ( $p>0.05$; Fig. 9C). Therefore, acute opioid-induced TLR4-dependent p38 and JNK

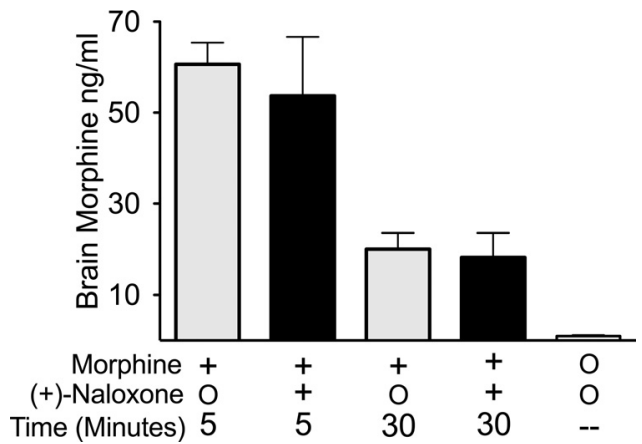

Figure 8. (+)-Naloxone does not alter morphine levels in brain (hippocampus). To define whether the results from the conditioned place preference or in vivo microdialysis studies may be attributed to blockade by (+)-naloxone of morphine reaching the CNS, morphine levels were measured in hippocampus, where this brain structure was chosen simply due to its size and ease of isolation. Rats were injected subcutaneously with $1 \mathrm{mg} / \mathrm{kg} \mathrm{(+)-naloxone} \mathrm{or} \mathrm{saline}$ $5 \mathrm{~min}$ before intraperitoneal $6 \mathrm{mg} / \mathrm{kg}$ morphine; naive rats served as negative controls. Either 5 or $30 \mathrm{~min}$ after injection, rats were decapitated, hippocampi were harvested, and morphine levels quantified by HPLC (Van Crugten et al., 1997; Doverty et al., 2001). No differences in brain levels of morphine were detected, comparing ( + )-naloxone and saline groups administered morphine (two-way ANOVA; $p>0.05$ ). Data are means \pm SEMs; $n=4 /$ group.
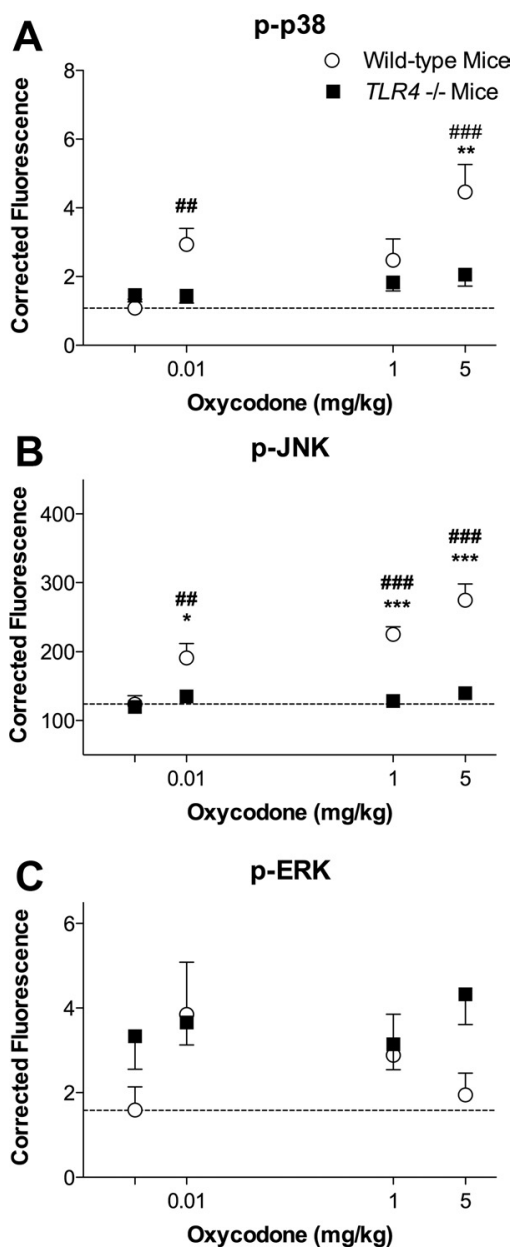

Figure 9. Oxycodone causes TLR4-dependent increases in p38 and JNK phosphorylation. TLR4 ${ }^{-1-}$ mice had significantly reduced oxycodone-induced MAP kinase signaling. Phosphorylation of MAPK proteins ( $\mathrm{p} 38$, JNK, and ERK) were measured from wild-type and TLR4 ${ }^{-1-}$ spinal cords following acute oxycodone administration. Oxycodone caused significant dose dependent elevations in the phosphorylation of $\mathrm{p} 38(\boldsymbol{A})$ and JNK $(\boldsymbol{B})$ in wild-type but not $T L R 4^{-1-}$ mice. An oxycodone effect was not observed in ERK phosphorylation (C). $n=$ $7-8$ animals per dose. Post hoc WT versus TLR4 ${ }^{-1-},{ }^{*} p<0.05,{ }^{* *} p<0.01,{ }^{* * *} p<0.001$. Post hoc vehicle versus dose, ${ }^{\# \#} p<0.01,{ }^{\# \# \#} p<0.001$. 
phosphorylation occurred temporally associated with TLR4dependent alterations in opioid pharmacodynamics.

Phase 3 control experiments: Can opioid agonists and (+)naloxone directly act at TLR4 or part of its extracellular signaling complex to induce the TLR4-dependent alterations in opioid reward?

All the evidence presented thus far implicates an opioid-induced, TLR4-dependent mechanism in altering opioid reward/reinforcement. However, this could occur via either direct opioid action at TLR4 or indirect activation of TLR4 signaling via an undefined mechanism(s). Therefore, a series of experiments were conducted to ascertain if any evidence for direct opioid interactions with TLR4 or its accessory protein MD2 could be found. Our recent publication has already outlined extensive evidence for direct morphine inter- actions with TLR4 and its accessory protein MD2 (Wang et al., 2012b). Similar oxycodone in silico data and oxycodone-induced TLR4-dependent NF- $\kappa \mathrm{B}$ signaling data have also previously been published (Hutchinson et al., 2010b), suggesting a similar mechanism of action to morphine. Here, we sought to examine the direct TLR4 activity of the fully synthetic 4-anilinopiperidine, remifentanil, and the (+)-4,5-epoxymorphinan isomer $(+)$-naloxone. Two independent lines of evidence were pursued for each compound to address this issue: (1) in silico docking of the ligand to the TLR4/MD2 complex, and (2) biophysical assessments of competitive binding of the ligand to MD2.

3A: Remifentanil and remifentanil acid dock in silico to the TLR4/MD2 complex. Morphine, remifentanil, and its opioid inactive metabolite, remifentanil acid, were assessed for their in silico docking to various conformational states of the TLR4/ MD2 complex using Vina and previously published TLR4/MD2 pdb files, to assess if any possibly relevant physicochemical interactions occurred. The metabolite of remifentanil was analyzed, in addition to the parent compound, given our prior finding that the opioid inactive metabolite of morphine proved to be a TLR4 agonist (Lewis et al., 2010). Interestingly, morphine's docking energy did not differ substantially between any of these conformations, but remifentanil and remifentanil acid both displayed lower docking energies when bound to the MD2 portion of the available conformational states. Moreover, all three compounds docked to the critical lipopolysaccharide binding domain of MD2 (Fig. 10). These data suggest that remifentanil and remifentanil acid displayed the physicochemical characteristics that may enable them to interact with the TLR4/MD2 complex.

3B: Remifentanil binds to MD2. Following on from the promising in silico data results, binding studies were conducted. To investigate whether remifenta-
Figure 10. Remifentanil, its major metabolite remifentanil acid, and morphine each dock to TLR4 and MD2 complex. Morphine remifentanil, and its opioid inactive metabolite, remifentanil acid, were determined to dock in silico to the lipopolysaccharidebinding domain of MD2. Comparisons of the docking energy estimates ( $y$-axis) for remifentanil and remifentanil acid across the multiple conformational states ( $x$-axis) suggest that such docking conformations preferred the formation of the active signaling heterodimer TLR4/MD2 complex rather than the MD2 alone conformation. In contrast, morphine failed to display any such docking energy preference to the TLR4/MD2 complex states, instead demonstrating high affinity for all states.
A

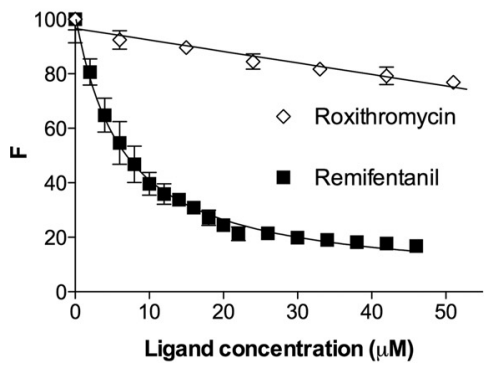

B

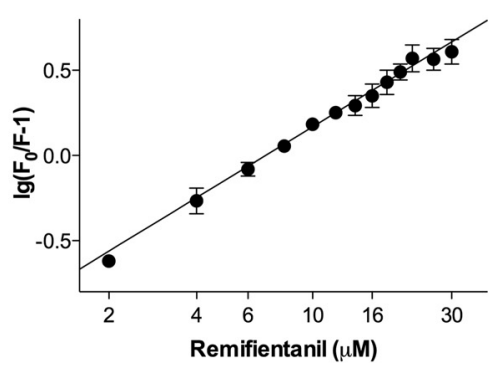

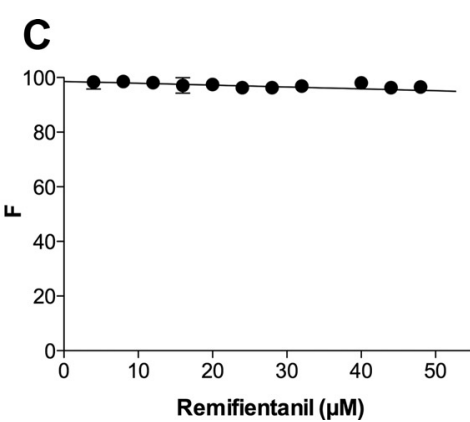

Figure 11. Biophysical determination of remifentanil binding to MD2 in vitro. $\boldsymbol{A}$, Titration curves of fluorescence quenching assay with the increasing drug concentrations. Remifentanil binds to $M D 2$ and causes the quenching of expressed MD2 intrinsic fluorescence in vitro, while roxithromycin, a compound used as a negative control, shows no MD2 binding activity. $K_{D}=6.0 \pm 1.1 \mu \mathrm{M}$ for the remifentanil-MD2 interaction. $\boldsymbol{B}$, Replotting the data from $\boldsymbol{A}$ according to the equation: $\lg \left(F_{0} / F-1\right)=-\lg K_{\mathrm{D}}+n \times \lg \left(\left[\right.\right.$ remifentanil]), revealing a slope of $1.06 \pm 0.07$ and a $K_{\mathrm{D}}=8.2 \pm$ $1.1 \mu \mathrm{m}$ for the remifentanil-MD2 interaction. $C$, Specificity of remifentanil binding is revealed by its failure to bind protein $A$. Remifentanil demonstrates negligible binding to a negative control protein, protein A. As the excitation, $280 \mathrm{~nm}$ was used, and emission at $308 \mathrm{~nm}$ (peak position) was plotted against the titrated remifentanil concentration. Note: the binding constants derived here are likely underestimating the affinity constants of remifentanil to MD2 due to the lack of cofactors found in vivo. Data are means \pm SEMs; $n=2$ replications per group. 


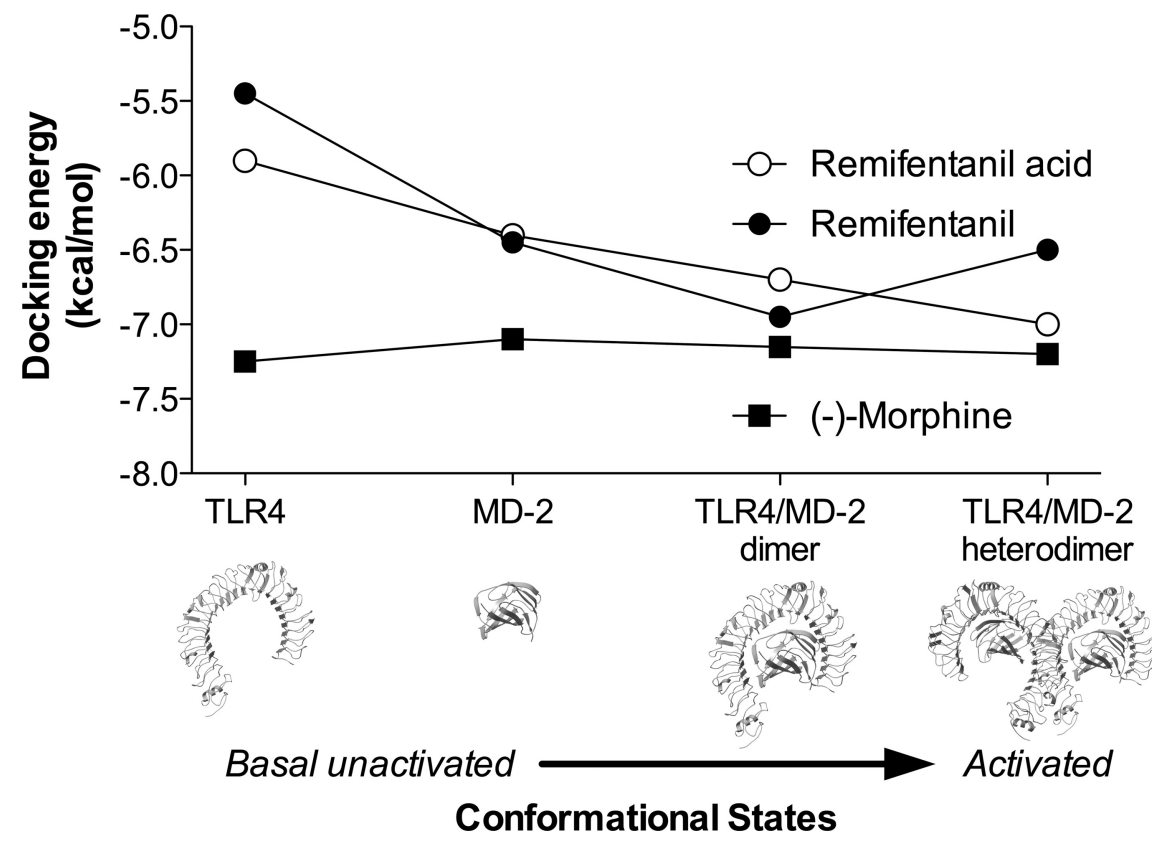

Figure 12. In silico docking of (+)-naloxone in the lipopolysaccharide-binding pocket of MD2, an essential coreceptor of TLR4. Morphine, remifentanil, and its opioid inactive metabolite, remifentanil acid (displayed as the overlapping stick symbol structures), were determined to dock in silico to the lipopolysaccharide-binding domain of MD2 (represented as a ribbon peptide), in a conformation that spatially overlap with (+)-naloxone (spatial cloud representing preferred docking conformation) and morphine in silico docking.
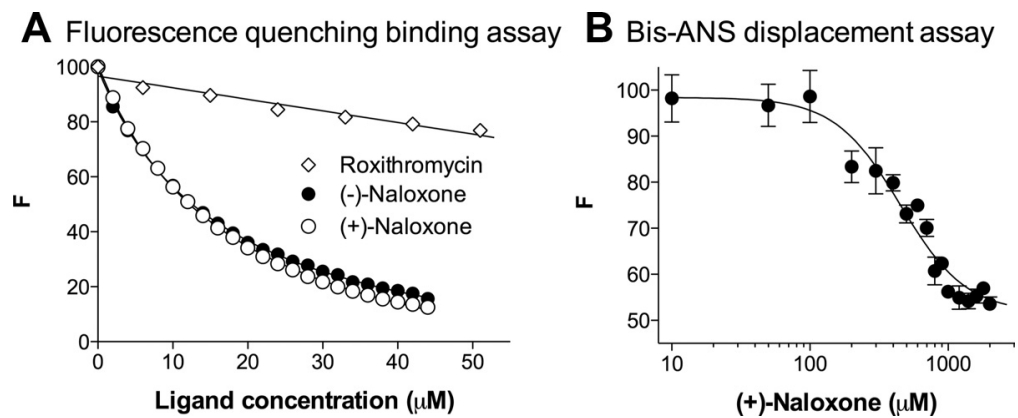

Figure 13. (+)-Naloxone binds to MD2 in vitro. $A$, Both (-)-naloxone and (+)-naloxone bind to MD2 and cause the quenching of expressed MD2 intrinsic fluorescence in vitro, while roxithromycin, a compound used as a negative control, shows no MD2 binding activity. $\boldsymbol{B},(+)$-Naloxone caused the decrease of Bis-ANS fluorescence from the Bis-ANS-MD2 complex, suggesting that (+)-naloxone replaces Bis-ANS binding to MD2. Note: the binding constants derived here are likely underestimating the affinity constants of $(+)$-naloxone to MD2 due to the lack of cofactors found in vitro. Data are means \pm SEMs; $n=2$ replications/group.

nil can bind to MD2, a fluorescence quenching assay was performed. As shown in Figure $11 \mathrm{~A}$, remifentanil caused the quenching of MD2 intrinsic fluorescence upon binding, while the negative control compound roxithromycin caused little quenching of MD2 fluorescence, demonstrating the specific binding of remifentanil to MD2. A dissociation constant $\left(K_{\mathrm{D}}\right)$ of $6.0 \pm 1.1$ $\mu \mathrm{M}$ was derived using a one-site binding model and nonlinear least-squares fit of MD2-remifentanil interaction. Figure $11 B$ shows the $\lg \left(F_{0} / F-1\right)$ versus $\lg ([$ remifentanil $] / \mu \mathrm{M})$ plot. A stoichiometry value of $1.06 \pm 0.07$ and $K_{\mathrm{D}}$ of $8.2 \pm 1.1 \mu \mathrm{M}$ were obtained for the binding of remifentanil to MD2, which lends further support to the one-site binding model. To eliminate the possibility that the observed MD2-remifentanil binding was due to Protein A tag-remifentanil interaction, we also tested the binding of remifentanil to Protein A (Fig. 11C) and no apparent quenching of Protein A intrinsic fluorescence was observed. The overall result excludes the possible Protein A tag-remifentanil binding. These data suggest that remifentanil is capable of direct binding to TLR4/MD2.

3C: In silico evidence that $(+)$-naloxone docks to the coreceptor MD2 of TLR4. Using the approach used in control Experiment $3 \mathrm{~A}$, complementary in silico data using previously available crystal structures (Park et al., 2009; Trott and Olson, 2010) show that docking of (+)-naloxone to MD2 spatially overlaps the docking of both morphine, remifentanil, and remifentanil acid, supporting competition at this binding pocket (Fig. 12). Therefore, $(+)$-naloxone has the necessary characteristics to allow for blockade of TLR4/MD2 binding to morphine and remifentanil.

3D: (+)-Naloxone binds to MD2. As noted above, prior studies have provided support that $(+)$-naloxone disrupts TLR4 signaling, but failed to identify the location along the TLR4 signaling cascade, even whether this involves an extracellular site versus intracellular site following activation of the TLR4/MD2 receptor complex. Here, the in vitro nonstereoselective binding of naloxone to purified expressed MD2 (Hutchinson et al., 2011) was assessed using ligand quenching of MD2 intrinsic fluorescence (Fig. 13A). Both (-)-naloxone and (+)naloxone bound MD2 and quenched MD2 intrinsic fluorescence with comparable affinities $(17.7 \pm 3.2 \mu \mathrm{M}$ and $16.6 \pm 4.7 \mu \mathrm{M}$, respectively). In comparison, the previously reported negative control roxithromycin (Resman et al., 2008) showed no MD2 binding activity, thus demonstrating specific binding of (+)-naloxone to MD2. Bis-ANS, a MD2 molecular probe, binds the lipopolysaccharide binding pocket of MD2 and its fluorescence intensity is enhanced when bound to MD2 (Mancek-Keber and Jerala, 2006). (+)-Naloxone decreased Bis-ANSMD2 complex fluorescence, suggesting that $(+)$-naloxone replaces Bis-ANS binding to MD2 (Fig. 13B). Collectively, these data suggest (+)-naloxone binds to the critical binding domain of MD2.

\section{Discussion}

Here, we provide evidence that TLR4 is a novel contributor to opioid reward behaviors and neurochemistry. Specifically, we demonstrated using (+)-naloxone-TLR4 pharmacological blockade, or MyD88-TLR4-dependent signaling genetic knockouts, that opioid-TLR4 signaling is a novel and important contributor to: (1) opioid reward behavior, as measured by CPP and self-administration; and (2) reward neurochemistry, through opioid-induced, but $(+)$-naloxone-sensitive, NAc shell extracellular dopamine elevations. Critically, these opioid-TLR4 actions are not simply a requirement for all opioid responses, since opioid-induced TLR4 signaling decreased opioid analgesia. We also conclude that opioids of diverse chemical structures can dock with the active domain of MD2, suggesting a direct mode of 
action of these agents acting as xenobiotic drugs to cause TLR4 signaling. Thus, it is hypothesized that opioids engage inflammatory CNS processes, acting as xenobiotic-associated molecular patterns (XAMPs) to activate TLR4, in addition to their previously characterized neuronal targets, thereby potentiating acute dopamine changes involved in opioid reward.

Several questions arise that warrant discussion regarding the changes in opioid reward: (1) "how" is opioid-TLR4 signaling involved; (2) "what" cell type(s) is/are contributing; and (3) "why" are opioid-TLR4 interactions acting in this manner? The "how" and "what" questions are indelibly linked, as "how" TLR4 contributes to opioid reward is dependent on "what" cells are expressing TLR4. As such, the two points will be discussed simultaneously.

Which TLR4-expressing cell type(s) contributes to opioid reward is unclear. Preliminary mRNA expression data using flow cytometry-assisted cell sorting of NAc micropunches suggests TLR4 mRNA is only found in microglia and not neurons (S. Bilbo, personal communication). Some examples of neuronal TLR4 expression exist (Diogenes et al., 2011; Ferraz et al., 2011), but their functional impact and how the very low MD2 expression by this cell type (Divanovic et al., 2005; Okun et al., 2011) impacts function is unknown. In contrast, it is clear that TLR4 is constitutively expressed by at least microglia (Bsibsi et al., 2002), macrophages (Fujihara et al., 2003), CNS vascular endothelial cells (Bsibsi et al., 2002), and some astrocytes (Holm et al., 2012). Thus, the highest likelihood is that the TLR4expressing cell type(s) contributing to opioid reward is among these.

Narrowing the list of TLR4/XAMP cellular targets aids in the identification of novel TLR4-dependent signaling pathways that may contribute to opioid reward behaviors and neurochemistry. TLR4 activation in non-neuronal cells leads to MyD88-, MAPK-, and NF- $\kappa$ B-dependent events (Okun et al., 2011). It is now apparent all these key signals occur temporally associated with TLR4-dependent altered opioid pharmacodynamic responses, with MyD88 and p38 MAPK (Zhang et al., 2012) specifically implicated in opioid reward behavior. Likely molecular mediators that result from such signaling include proinflammatory cytokines, and these have been proposed as potential contributors to opioid reward (Coller and Hutchinson, 2012). Such conclusions are supported by their neuroexcitatory effects (Watkins et al., 2009) of glutamate transporter downregulation (Wang et al., 2003), GABA receptor downregulation (Stellwagen et al., 2005), upregulation of AMPA/NMDA expression and function (De et al., 2003), and enhancement of neurotransmitter release (Youn et al., 2008). Proinflammatory cytokines could therefore amplify opioid-induced neuronal activity in drug reward circuitry at multiple points, but the specifics of the underlying mechanisms remain to be determined.

Such a TLR4-dependent proinflammatory hypothesis of opioid reward aligns with prior literature implicating glia. For example, morphine increased NAc astrocyte and microglial activation marker mRNA expression (Schwarz et al., 2011), morphineinduced CPP concomitantly induced activation of NAc microglial p38 (Zhang et al., 2012), and NAc microinjection of a microglial or p38 inhibitor blocked both acquisition and maintenance of morphine-induced CPP (Zhang et al., 2012). These regional specific studies support earlier findings that systemic broad-spectrum glial activation inhibitors suppress morphineinduced dopamine elevations in the NAc shell [ibudilast (Bland et al., 2009)] and morphine-induced CPP [propentofylline, minocycline (Narita et al., 2006; Hutchinson et al., 2008a)]. Inter- estingly, morphine reward and dependence/withdrawal may differ regarding TLR4 involvement. Despite broad-spectrum glial attenuators reducing proinflammation-linked opioid dependence/withdrawal (Hutchinson et al., 2008a, 2009; Liu et al., 2011), TLR $4^{-1-}$ mice are not protected against opioid withdrawal, suggestive of a TLR4-independent mechanism (Liu et al., 2011).

The third point is "why" TLR4 is involved in opioid reward. The evolutionary reasons for TLR4 recognizing XAMPs, including opioids, and this central immune signal interacting with mesolimbic dopamine reward pathways are unknown. It is clear that TLR4 activation by itself does not produce behavioral reward (Narita et al., 2006). (+)-Naloxone action is not an evolutionary control measure since $(+)$-naloxone is a fully synthetic unnatural compound. However, as we have presented here, these small molecules dock to the same domain in MD2 as lipopolysaccharide, suggesting some possible common threat-detection system.

Questions also arise as to why this opioid-TLR4/MD2 interaction has not previously been reported in binding or behavioral studies. Such data have been reported but not followed up. For example, the seminal research of Takagi et al. (1960) demonstrated the relevance of nonclassical nonstereoselective opioid actions, and Goldstein et al. (1971) found a 30-fold greater abundance of nonstereoselective but saturable opioid binding sites compared with saturable stereoselective opioid binding. A key issue in in vitro systems, which leads to significant variability, is that MD2 is extracellular, and can therefore be easily lost from or not included in assays, as we have exemplified previously (Hutchinson et al., 2010b).

An important caveat to any pharmacological studies is the specificity of the agonist and the antagonist used. Collaboratively, we have screened (+)-naloxone on over 70 known receptors, enzymes, second messengers, ion channels, and transporters (our unpublished data), finding no significant activity at any of these important targets. These data also extend our prior observation that $(+)$-naloxone blocks TLR4, but not TLR2, signaling (Lewis et al., 2012). Other non-TLR4 actions of this agent have been reported that theoretically could alter opioid pharmacodynamics, such as activity at Filamin A (Burns and Wang, 2010) and NADPH oxidase (Wang et al., 2012a). However, given the TLR4-MyD88 dependent signaling required to elicit opioid CPP presented here, and our previous data showing no additional $(+)$-naloxone-induced potentiation of morphine analgesia in $T L R 4^{-1-}$ mice (Hutchinson et al., 2010b), suggest that these documented $(+)$-naloxone actions at Filamin A and NADPH oxidase are not involved in modifying these opioid pharmacodynamic actions. It is possible that other sites of $(+)$-naloxone action may be downstream from the $(+)$-naloxone-TLR4/MD2 activity rendering them less relevant to opioid reward, but could prove important for other TLR4 ligands such as PAMPs or DAMPs. Similarly, it is plausible that opioids may be activating other TLRs (He et al., 2011; Zhang et al., 2011), in a fashion that is codependent on TLR4-MyD88-dependent signaling. Such possibilities will require further evaluation.

Additional studies are needed to understand the in vivo (+)naloxone and opioid TLR4/MD2 potency in these and other models. It is apparent from the in vitro biophysical characterization of ligand-MD2 interactions conducted to date (Wang et al., 2012 b) that this is a low affinity site. Moreover, in vivo agonist concentrations may fall below the binding constant estimates. Such discrepancies suggest other factors or chaperones may be involved that facilitate this interaction, which are absent in the in 
vitro systems. Other differences in $(+)$-naloxone requirement were also observed, with morphine CPP and NAc dopamine elevations nearly completely blocked by $1 \mathrm{mg} / \mathrm{kg}(+)$-naloxone, while higher doses were needed for the attenuation of remifentanil self-administration. Some elevations in NAc dopamine were anticipated to occur in the absence of opioid-TLR4 actions, suggesting tonal endogenous TLR4 activity is required for elevated mesolimbic dopamine reward function. Interestingly, Dunwiddie et al. (1982) established that hippocampal pyramidal cell spontaneous activity in the CA1 region was nonstereoselectively inhibited by naloxone, providing further impetus to examine the neuronal consequences of this TLR4-opioid response. An additional difference in $(+)$-naloxone potency across the three different models may reflect the nature of the three models and the opioids studied. The CPP and NAc dopamine microdialysis studies were conducted after limited opioid/XAMP exposure. However, the remifentanil self-administration studies were conducted in rats that had been repetitively trained on cocaine followed by repeated remifentanil. Therefore, if both these treatments were acting as XAMPs, they may have sensitized the TLR4 system (Bowers and Kalivas, 2003), which (+)-naloxone had to overcome via higher doses.

If activation of CNS TLR4 signaling by diverse opioid structures reflects an innate immune system response to xenobiotics (Hutchinson et al., 2011), then other drugs of abuse may be equally viewed as chemical compounds that are foreign to living organisms. Hence, multiple drugs of abuse may cause XAMP-TLR4 signaling that could also contribute to their reinforcing effects. Given that drugs of abuse including alcohol (He and Crews, 2008), cocaine (Bowers and Kalivas, 2003), amphetamine (Thomas et al., 2004b), and methamphetamine (Thomas et al., 2004a) are associated with glial activation, and that systemic glial activation inhibitors have been reported to suppress the reinforcing effects of methamphetamine (Narita et al., 2006; Beardsley et al., 2010; Fujita et al., 2012), amphetamine (Sofuoglu et al., 2011), and alcohol (Agrawal et al., 2011), examining whether XAMP-TLR4 activity contributes to the rewarding properties of diverse drugs of abuse is warranted (Coller and Hutchinson, 2012).

\section{Notes}

Supplemental material for this article is available at http://goo.gl/1f0ox; with supplemental data for the screening of $(+)$-naloxone on $>70$ known receptors, enzymes, second messengers, ion channels, and transporters. This material has not been peer reviewed.

\section{References}

Agrawal RG, Hewetson A, George CM, Syapin PJ, Bergeson SE (2011) Minocycline reduces ethanol drinking. Brain Behav Immun 25 [Suppl 1]:S165-S169.

Beardsley PM, Shelton KL, Hendrick E, Johnson KW (2010) The glial cell modulator and phosphodiesterase inhibitor, AV411 (ibudilast), attenuates prime- and stress-induced methamphetamine relapse. Eur J Pharmacol 637:102-108.

Bland ST, Hutchinson MR, Maier SF, Watkins LR, Johnson KW (2009) The glial activation inhibitor AV411 reduces morphine-induced nucleus accumbens dopamine release. Brain Behav Immun 23:492-497.

Bowers MS, Kalivas PW (2003) Forebrain astroglial plasticity is induced following withdrawal from repeated cocaine administration. Eur J Neurosci 17:1273-1278.

Bsibsi M, Ravid R, Gveric D, van Noort JM (2002) Broad expression of Toll-like receptors in the human central nervous system. J Neuropathol Exp Neurol 61:1013-1021.

Buchanan MM, Hutchinson M, Watkins LR, Yin H (2010) Toll-like receptor 4 in CNS pathologies. J Neurochem 114:13-27.
Burns LH, Wang HY (2010) PTI-609: a novel analgesic that binds filamin A to control opioid signaling. Recent Pat CNS Drug Discov 5:210-220.

Coller JK, Hutchinson MR (2012) Implications of central immune signaling caused by drugs of abuse: Mechanisms, mediators and new therapeutic approaches for prediction and treatment of drug dependence. Pharmacol Ther 134:219-245.

Compton WM, Volkow ND (2006) Abuse of prescription drugs and the risk of addiction. Drug Alcohol Depend 83 [Suppl 1]:S4-S7.

De A, Krueger JM, Simasko SM (2003) Tumor necrosis factor alpha increases cytosolic calcium responses to AMPA and $\mathrm{KCl}$ in primary cultures of rat hippocampal neurons. Brain Res 981:133-142.

Diogenes A, Ferraz CC, Akopian AN, Henry MA, Hargreaves KM (2011) LPS sensitizes TRPV1 via activation of TLR4 in trigeminal sensory neurons. J Dent Res 90:759-764.

Divanovic S, Trompette A, Atabani SF, Madan R, Golenbock DT, Visintin A, Finberg RW, Tarakhovsky A, Vogel SN, Belkaid Y, Kurt-Jones EA, Karp CL (2005) Inhibition of TLR-4/MD-2 signaling by RP105/MD-1. J Endotoxin Res 11:363-368.

Doverty M, Somogyi AA, White JM, Bochner F, Beare CH, Menelaou A, Ling W (2001) Methadone maintenance patients are cross-tolerant to the antinociceptive effects of morphine. Pain 93:155-163.

Dunwiddie TV, Perez-Reyes E, Rice KC, Palmer MR (1982) Stereoselectivity of opiate antagonists in rat hippocampus and neocortex: responses to $(+)$ and $(-)$ isomers of naloxone. Neuroscience 7:1691-1702.

Ferraz CC, Henry MA, Hargreaves KM, Diogenes A (2011) Lipopolysaccharide from Porphyromonas gingivalis sensitizes capsaicin-sensitive nociceptors. J Endod 37:45-48.

Fujihara M, Muroi M, Tanamoto K, Suzuki T, Azuma H, Ikeda H (2003) Molecular mechanisms of macrophage activation and deactivation by lipopolysaccharide: roles of the receptor complex. Pharmacol Ther 100:171-194.

Fujita Y, Kunitachi S, Iyo M, Hashimoto K (2012) The antibiotic minocycline prevents methamphetamine-induced rewarding effects in mice. Pharmacol Biochem Behav 101:303-306.

Goldstein A, Lowney LI, Pal BK (1971) Stereospecific and nonspecific interactions of the morphine congener levorphanol in subcellular fractions of mouse brain. Proc Natl Acad Sci U S A 68:1742-1747.

Hargreaves K, Dubner R, Brown F, Flores C, Joris J (1988) A new and sensitive method for measuring thermal nociception in cutaneous hyperalgesia. Pain 32:77-88.

He J, Crews FT (2008) Increased MCP-1 and microglia in various regions of the human alcoholic brain. Exp Neurol 210:349-358.

He L, Li H, Chen L, Miao J, Jiang Y, Zhang Y, Xiao Z, Hanley G, Li Y, Zhang X, LeSage G, Peng Y, Yin D (2011) Toll-like receptor 9 is required for opioid-induced microglia apoptosis. PLoS One 6:e18190.

Hiranita T, Soto PL, Kohut SJ, Kopajtic T, Cao J, Newman AH, Tanda G, Katz JL (2011) Decreases in cocaine self-administration with dual inhibition of dopamine transporter and sigma receptors. J Pharmacol Exp Ther 339:662-677.

Holm TH, Draeby D, Owens T (2012) Microglia are required for astroglial toll-like receptor 4 response and for optimal TLR2 and TLR3 response. Glia 60:630-638.

Hutchinson MR, Northcutt AL, Chao LW, Kearney JJ, Zhang Y, Berkelhammer DL, Loram LC, Rozeske RR, Bland ST, Maier SF, Gleeson TT, Watkins LR (2008a) Minocycline suppresses morphine-induced respiratory depression, suppresses morphine-induced reward, and enhances systemic morphine-induced analgesia. Brain Behav Immun 22:1248-1256.

Hutchinson MR, Coats BD, Lewis SS, Zhang Y, Sprunger DB, Rezvani N, Baker EM, Jekich BM, Wieseler JL, Somogyi AA, Martin D, Poole S, Judd CM, Maier SF, Watkins LR (2008b) Proinflammatory cytokines oppose opioid-induced acute and chronic analgesia. Brain Behav Immun 22:1178-1189.

Hutchinson MR, Lewis SS, Coats BD, Skyba DA, Crysdale NY, Berkelhammer DL, Brzeski A, Northcutt A, Vietz CM, Judd CM, Maier SF, Watkins LR, Johnson KW (2009) Reduction of opioid withdrawal and potentiation of acute opioid analgesia by systemic AV411 (ibudilast). Brain Behav Immun 23:240-250.

Hutchinson MR, Loram LC, Zhang Y, Shridhar M, Rezvani N, Berkelhammer D, Phipps S, Foster PS, Landgraf K, Falke JJ, Rice KC, Maier SF, Yin H, Watkins LR (2010a) Evidence that tricyclic small molecules may possess toll-like receptor and myeloid differentiation protein 2 activity. Neuroscience 168:551-563. 
Hutchinson MR, Zhang Y, Shridhar M, Evans JH, Buchanan MM, Zhao TX, Slivka PF, Coats BD, Rezvani N, Wieseler J, Hughes TS, Landgraf KE, Chan S, Fong S, Phipps S, Falke JJ, Leinwand LA, Maier SF, Yin H, Rice KC et al. (2010b) Evidence that opioids may have toll-like receptor 4 and MD-2 effects. Brain Behav Immun 24:83-95.

Hutchinson MR, Shavit Y, Grace PM, Rice KC, Maier SF, Watkins LR (2011) Exploring the neuroimmunopharmacology of opioids: an integrative review of mechanisms of central immune signaling and their implications for opioid analgesia. Pharmacol Rev 63:772-810.

Ikemoto S (2007) Dopamine reward circuitry: two projection systems from the ventral midbrain to the nucleus accumbens-olfactory tubercle complex. Brain Res Rev 56:27-78.

Lakowicz JR (2006) Principles of fluorescence spectroscopy, 2nd Ed. New York: Springer-Verlanger.

Laviolette SR, Nader K, van der Kooy D (2002) Motivational state determines the functional role of the mesolimbic dopamine system in the mediation of opiate reward processes. Behav Brain Res 129:17-29.

Lewis SS, Hutchinson MR, Rezvani N, Loram LC, Zhang Y, Maier SF, Rice KC, Watkins LR (2010) Evidence that intrathecal morphine-3-glucuronide may cause pain enhancement via toll-like receptor 4/MD-2 and interleukin1beta. Neuroscience 165:569-583.

Lewis SS, Loram LC, Hutchinson MR, Li C-M, Zhang Y, Maier SF, Huang Y, Rice KC, Watkins LR (2012) (+)-Naloxone, an opioid-inactive toll-like receptor 4 signaling inhibitor, reverses multiple models of chronic neuropathic pain in rats. J Pain:invited revision in review.

Liu L, Coller JK, Watkins LR, Somogyi AA, Hutchinson MR (2011) Naloxone-precipitated morphine withdrawal behavior and brain ILlbeta expression: comparison of different mouse strains. Brain Behav Immun 25:1223-1232.

Mancek-Keber M, Jerala R (2006) Structural similarity between the hydrophobic fluorescent probe and lipid A as a ligand of MD-2. FASEB J 20:1836-1842.

Manchikanti L (2006) Prescription drug abuse: what is being done to address this new drug epidemic? Testimony before the subcommittee on criminal justice, drug policy and human resources. Pain Physician 9:287-321.

Matic M, Mahns A, Tsoli M, Corradin A, Polly P, Robertson GR (2007) Pregnane $\mathrm{X}$ receptor: promiscuous regulator of detoxification pathways. Int J Biochem Cell Biol 39:478-483.

Milligan ED, Hinde JL, Mehmert KK, Maier SF, Watkins LR (1999) A method for increasing the viability of the external portion of lumbar catheters placed in the spinal subarachnoid space of rats. J Neurosci Methods 90:81-86.

Narita M, Miyatake M, Shibasaki M, Shindo K, Nakamura A, Kuzumaki N, Nagumo Y, Suzuki T (2006) Direct evidence of astrocytic modulation in the development of rewarding effects induced by drugs of abuse. Neuropsychopharmacology 31:2476-2488.

Okun E, Griffioen KJ, Mattson MP (2011) Toll-like receptor signaling in neural plasticity and disease. Trends Neurosci 34:269-281.

Panlilio LV, Katz JL, Pickens RW, Schindler CW (2003) Variability of drug self-administration in rats. Psychopharmacology 167:9-19.

Park BS, Song DH, Kim HM, Choi BS, Lee H, Lee JO (2009) The structural basis of lipopolysaccharide recognition by the TLR4-MD-2 complex. Nature 458:1191-1195.

Paxinos G, Watson C (1998) The rat brain in stereotaxic coordinates. San Diego: Academic.

Resman N, Gradisar H, Vasl J, Keber MM, Pristovsek P, Jerala R (2008) Taxanes inhibit human TLR4 signaling by binding to MD-2. FEBS Lett 582:3929-3934.
Schwarz JM, Hutchinson MR, Bilbo SD (2011) Early-life experience decreases drug-induced reinstatement of morphine CPP in adulthood via microglial-specific epigenetic programming of anti-inflammatory IL-10 expression. J Neurosci 31:17835-17847.

Sofuoglu M, Mooney M, Kosten T, Waters A, Hashimoto K (2011) Minocycline attenuates subjective rewarding effects of dextroamphetamine in humans. Psychopharmacology 213:61-68.

Stellwagen D, Beattie EC, Seo JY, Malenka RC (2005) Differential regulation of AMPA receptor and GABA receptor trafficking by tumor necrosis factor-alpha. J Neurosci 25:3219-3228.

Takagi K, Fukuda H, Watanabe M, Sato M (1960) Studies on antitussives. III. (+)-Morphine and its derivatives. Yakugaku Zasshi 80:1506-1509.

Thomas DM, Walker PD, Benjamins JA, Geddes TJ, Kuhn DM (2004a) Methamphetamine neurotoxicity in dopamine nerve endings of the striatum is associated with microglial activation. J Pharmacol Exp Ther 311:1-7.

Thomas DM, Dowgiert J, Geddes TJ, Francescutti-Verbeem D, Liu X, Kuhn DM (2004b) Microglial activation is a pharmacologically specific marker for the neurotoxic amphetamines. Neurosci Lett 367:349-354.

Trott O, Olson AJ (2010) AutoDock Vina: improving the speed and accuracy of docking with a new scoring function, efficient optimization, and multithreading. J Comput Chem 31:455-461.

Van Crugten JT, Somogyi AA, Nation RL, Reynolds G (1997) The effect of old age on the disposition and antinociceptive response of morphine and morphine- 6 beta-glucuronide in the rat. Pain 71:199-205.

Vargas-Perez H, Ting-A Kee R, Walton CH, Hansen DM, Razavi R, Clarke L, Bufalino MR, Allison DW, Steffensen SC, van der Kooy D (2009) Ventral tegmental area BDNF induces an opiate-dependent-like reward state in naive rats. Science 324:1732-1734.

Wang Q, Zhou H, Gao H, Chen SH, Chu CH, Wilson B, Hong JS (2012a) Naloxone inhibits immune cell function by suppressing superoxide production through a direct interaction with gp9lphox subunit of NADPH oxidase. J Neuroinflammation 9:32.

Wang X, Loram LC, Ramos K, de Jesus AJ, Thomas J, Reddy A, Somogyi AA, Hutchinson MR, Watkins LR, Yin H (2012b) Morphine activates neuroinflammation in a manner parallel to endotoxin. Proc Natl Acad Sci U S A 109:6325-6330.

Wang Z, Pekarskaya O, Bencheikh M, Chao W, Gelbard HA, Ghorpade A, Rothstein JD, Volsky DJ (2003) Reduced expression of glutamate transporter EAAT2 and impaired glutamate transport in human primary astrocytes exposed to HIV-1 or gp120. Virology 312:60-73.

Watkins LR, Hutchinson MR, Rice KC, Maier SF (2009) The "toll" of opioid-induced glial activation: improving the clinical efficacy of opioids by targeting glia. Trends Pharmacol Sci 30:581-591.

Wolf LK (2009) New software and websites for the chemical enterprise. Chem Engin News 87:31.

Yirmiya R, Goshen I (2011) Immune modulation of learning, memory, neural plasticity and neurogenesis. Brain Behav Immun 25:181-213.

Youn DH, Wang H, Jeong SJ (2008) Exogenous tumor necrosis factor-alpha rapidly alters synaptic and sensory transmission in the adult rat spinal cord dorsal horn. J Neurosci Res 86:2867-2875.

Zhang XQ, Cui Y, Chen Y, Na XD, Chen FY, Wei XH, Li YY, Liu XG, Xin WJ (2012) Activation of $\mathrm{p} 38$ signaling in the microglia in the nucleus accumbens contributes to the acquisition and maintenance of morphineinduced conditioned place preference. Brain Behav Immun 26:318-325.

Zhang Y, Li H, Li Y, Sun X, Zhu M, Hanley G, Lesage G, Yin D (2011) Essential role of toll-like receptor 2 in morphine-induced microglia activation in mice. Neurosci Lett 489:43-47. 